\title{
SOBRE LA CONSTITUCIÓN. CONCEPTO, COMPOSICIÓN Y MECANISMOS
}

\author{
RAÚL GUSTAVO FERREYRA
}




\section{SUMARIO}

I. APERTURA: HECHOS E IDEAS. II. ¿QUÉ ES UNA CONSTITUCIÓN? INVENTARIO. II.1. Preliminar. II.2. Acepciones. II.3. Brevísima ojeada sobre el recorrido histórico de «constitución». II.3.A. La fuerza normativa de lo fáctico. II.3.B. Paradigmas normativos. II.3.B bis. Interludio: las utopías de Thomas Paine. II.3.C. La hoja de papel. II.3.D. En oposición a Carl Schmitt. II.3.E. La teoría pura del Derecho. II.4. Interludio: el trialismo de Germán J. Bidart Campos. III. SIGNIFICADO DE CONSTITUCIÓN. (i) Primacía. (ii) Jerarquía. (iii) Elasticidad. (iv) Apertura. (v) Unidad. (vi) La coherencia. (vii) La soberanía. (viii) Organización. (ix) Identidad. (x) Vinculación. IV. LAS PARTES. IV.1. Presentación básica. IV.2. Composición estricta. IV.3. Simples declaraciones. IV.3.A. El preámbulo de una constitución. IV.3.B. Disposiciones transitorias. IV.4. Los derechos y deberes fundamentales. IV.4.A. Los derechos fundamentales. IV.4.B. Los deberes u obligaciones. IV.5. El poder y su control. IV.6. La reforma. V. MECANISMOS GARANTISTAS. V.1. Diseño. V.2.A. Garantías de la constitución. V.2.A bis. Entreacto. Interpretación y control judicial de la constitucionalidad. V.2.B. Garantías de los derechos fundamentales. V.2.C. La garantía orgánica para la defensa de los derechos fundamentales. V.2.D. Garantía supraestatal para la defensa de los derechos fundamentales estatuidos por el derecho de la constitución. VI. CLAUSURA. 


\title{
SOBRE LA CONSTITUCIÓN. CONCEPTO, COMPOSICIÓN Y MECANISMOS
}

\author{
RAÚL GUSTAVO FERREYRA ${ }^{1}$ \\ Catedrático de Derecho Constitucional \\ Facultad de Derecho \\ Universidad de Buenos Aires \\ Doctor de la UBA
}

\section{APERTURA: HECHOS E IDEAS}

El hombre comienza, desarrolla y finaliza su vida en dos ámbitos o realidades: el natural o físico y el comunitario e individual. La historia atestigua, pero ni la ciencia ni la tecnología actual se encuentran en condiciones de predecir ni retrodecir concluyentemente sobre el enigmático momento original o sobre la existencia del momento final o fecha de caducidad del homo sapiens.

La naturaleza se constituye por una totalidad de cosas físicas (concretas), sus estados y procesos; su descripción más o menos exacta encierra siempre una colección de hechos (estáticos y cinéticos), con el detalle de su uniformidad, regularidad y estabilidad.

La comunidad se constituye por una totalidad de cosas ideales (constructos), sus estados y procesos; encierra una colección de normas, con el detalle de su creación, validez y cambio. Las preguntas del hombre para consigo mismo, el abordaje y penetración en su inherente individualidad, la búsqueda y afirmación

\footnotetext{
${ }^{1}$ Dedico esta contribución a la doctora Alicia Pierini.
} 
de la identidad recóndita o evidente de su propio ser y de su existencia son comprendidas con un proceso semejante: ideas o pensamientos. La propia configuración o formulación de una norma es un hecho porque forma parte de la realidad mundana; la norma creada o producida no es un hecho físico, obviamente sí lo es el dato elementalísimo de su constancia.

La relación del hombre «en» y «con» cada uno de estos ámbitos o realidades fundamentales generó y seguirá generando diferentes conflictos y armonías. En miles de años, el hombre ha descubierto, inventado o creado, según los casos y sin importar ordenación cronológica, las herramientas, el fuego, las máquinas, la agricultura, el lenguaje, la escritura, la filosofía, las artes, el saber científico y el conocimiento tecnológico (entre ellos, nuestra tecnología social: el Derecho). La razón y la experiencia permiten al hombre ser y desarrollar la única especie capaz de transmitir, a la siguiente generación, conocimientos y habilidades, con bastante objetividad. También se comunican tradiciones, muchas de ellas funestas o híbridas por los temores o tabúes que contienen y engendran o por la fuerte inclinación al reposo que suscitan. El hombre es el único creador de las normas sociales. Fueron las normas, sus ideas, precisamente, las que han permitido la elevación del hombre por sobre el resto del reino animal. ¿O acaso hay otra razón?

La distinción entre mundo natural y mundo cultural no goza de aceptación universal ${ }^{2}$. Hay quienes creen o sostienen que sólo existe una realidad irreductible: los hechos, razón por la cual las normas son establecidas por voluntad del creador, de los creadores, o del dominador del universo o dominadores del universo que puede o pueden ser un dictador o dictadores. Contrariamente, hay quienes piensan que todos los hechos deben ser reducidos a normas, razón por la cual las normas serían o constituyen la única realidad verdadera y por ende irreductible. De modo crítico, hay quienes sostienen que la producción de las normas sociales

${ }^{2}$ Nadie puede establecerlo fehacientemente. Rodolfo Mondolfo enseñó que la reflexión sobre el mundo humano precedió a la reflexión sobre el mundo natural. (En los orígenes de la filosofía de la cultura, Hachette, Buenos Aires, 1960). Decir por tanto que la antropología precedió a la cosmología o viceversa, en estas escuetísimas líneas, constituiría una aseveración abierta a sospecha, pero un homenaje al filósofo. Quizás, un fragmento del Protágoras de Platón conserve alguna utilidad literaria, porque no creo que sea posible fijar un único momento en que acaeció la distinción, menos aún en términos modernos de la filosofía de la cultura. Se puso en boca del sofista: «Porque creo que saben que lo bello y su contrario se dan en los hombres por la naturaleza o el azar. En cambio, cuando se trata de bienes [la justicia] que creen que se dan en los hombres a partir del cuidado, el ejercicio y la enseñanza, si alguien, en lugar de tenerlos, tuviera los males contrarios, ahí se dan las irritaciones, los castigos y las amonestaciones contra ellos» (Platón: Protágoras, Losada, Buenos Aires, 2006, pp. 141-142). En este escrito, naturaleza y convención, hechos naturales e ideas culturales constituyen dominios diferenciados, pero no contrapuestos. 
es una convención ${ }^{3}$, por lo que el hombre es el responsable de las mismas, razón por la cual, aunque se trata de dominios eminentes, resulta aconsejable tender un puente entre el ser y el deber ser, sin pausas, constantemente y con firmeza.

Toda constitución posee o aspira a poseer una comprensión cabal de la realidad política; ciertamente, dicha comprensión involucra un estado de cosas ideal pensado por el legislador constituyente. Los datos del mundo físico deben formar parte de la constitución. En consecuencia, la idealidad constitucional tiene que observar un «un mínimo de respeto por lo que es, tal cual es» ${ }^{4}$, porque si no puede tener concreción en la realidad, la creación normativa no se sustenta en un fundamento racional.

El homo sapiens exhibe miles de años en su recorrido por la Tierra. Sin embargo, la organización y unidad comunitaria con fundamento coherente en una «constitución», basada en múltiples y contradictorias ideas sobre la libertad, la igualdad, el pluralismo y la tolerancia, no supera los 250 años; o sea, comparativamente, se trata de un instrumento reciente.

Para conocer y comprender los rasgos del Derecho constitucional es imprescindible conocer, previamente, la fuente de la que emana y que lo determina: la constitución. Por lo tanto, la determinación del significado o concepto de constitución resulta una tarea preliminar. Porque, como se afirma, el objeto o cosa constitución es el origen del Derecho constitucional. Sostengo, con inspiración abierta en la afirmación cartesiana ${ }^{5}$, que todo el Derecho es como un árbol: sus raíces son la constitución (y las fuentes externas, Derecho internacional de los Derechos Humanos —DDHH_- cuando observan igual jerarquía); su tronco, el Derecho constitucional, y las ramas que nacen de su tronco, cada uno de las disciplinas jurídicas: Derecho Penal, Derecho Civil, etcétera.

En la sección II se examinan diversos significados de constitución; con azar o sin él, se eligen enfoques desarrollados en la historia de las ideas en los que predomina la conceptuación de la constitución, ya sea firmemente como hecho (una conducta realizada por los hombres, sin importar si fue normada), o bien indiscutiblemente como norma (una determinación de conducta que debe ser realizada por los hombres, sin importar si es cumplida). También, en la aludida sección, se

3 V. Popper, Karl Raimund: La sociedad abierta y sus enemigos, Paidós, Madrid, 1992, pp. 67-92.

${ }^{4}$ Zaffaroni, Eugenio Raúl et al: Manual de Derecho Penal, Ediar, Buenos Aires, 2010, p. 77.

5 Descartes, René: Principia philosophiae (Principles of Philosophy). Translation with explanatory notes by Valentine Rodger and Reese P. Miller (Reprint ed.), Dordrecht, Reidel, 1983. Letter of the author to the French translator of the Principles of Philosophy serving for a Preface: «... Thus, all Philosophy is like a tree, of which Metaphysics is the root, Physics the trunk, and all the other sciences the branches that grow out of this trunk, which are reduced to three principal, namely, Medicine, Mechanics, and Ethics...». 
inscriben algunas ideas de filósofos que se consideran relevantes para el debate; en paralelo, se introducen modelos normativos que se consideran paradigma.

En la sección III se presenta el significado propio de constitución. Que ningún lector se enfade: si ahora mismo hago una advertencia preliminar, que pronuncia el significado, no cuento el final de la pieza, porque robustamente trato de problematizar. En la citada inteligencia, reservo, pues, en este escrito el empleo de constitución, a secas, para identificar a una norma: a) sobre normas; b) elaborada por una autoridad, que se funda y representa el poder de los ciudadanos; c) con fuerza obligatoria; d) cuyo texto, regular y uniformemente, consta en un documento escrito; e) dirigida a ciudadanos y servidores públicos, y f) cuya principal finalidad, antes que un consuelo, consiste, precisamente, en la realización del ámbito de su normatividad: que cierto estado de cosas debe ser; por ende, en esta propia conceptuación, la distinción entre constitución formal y material carece de sentido y cae por su propio peso.

Luego, en la sección IV, se ilustra sobre las piezas o partes de esta cosa denominada mundialmente constitución. No es novedad: todo Estado hoy en día aspira a ser un Estado constitucional («tanto Estado como el que constituya la constitución» ${ }^{6}$ ), que no es semejante a Estado con constitución.

La sección $\mathrm{V}$ se destina al examen del principal mecanismo de realización de la constitución: las garantías.

Además, se advierte, que en las secciones III, IV y V se razona y observa, básicamente, sobre el entramado normativo conocido por todos como Constitución federal de la Argentina (en adelante CF o CFA, sin distinción).

\section{II. ¿QUÉ ES UNA CONSTITUCIÓN? INVENTARIO}

\section{II.1. Preliminar}

Quienes visitan el saber jurídico comprueban que la noción de constitución posee importancia clave. Lector o pensador, investigador o jurista, pueden también preguntarse acerca de los fundamentos, la naturaleza y, finalmente, del porqué de tal aseveración.

${ }^{6}$ V. Häberle, Peter: El Estado constitucional, UNAN, IIJ, México D.F., 2003, p. 14. 


\section{II.2. Acepciones}

La literatura sobre los conceptos atribuibles a constitución es enorme. No se realiza aquí reporte completo.

De la variedad de significados que el Diccionario de la Real Academia Española (DRAE) describe y ordena para el vocablo constitución, por la importancia que tienen para las ideas que en este sitio se escriben, es interesante traer a colación dos de ellos, en razón de que, en cierto sentido, son útiles para mostrar la evolución de «como de hecho» un Estado estaba constituido a la idea de «cómo debe configurarse» — por Derecho- su constitución estatal. Veamos: a) El primero de ellos afirma que «constitución» es la «esencia y calidades de una cosa que la constituyen como es y la diferencian de las demás». b) El segundo señala que «constitución» es la «ley fundamental de un Estado que define el régimen básico de los derechos y libertades de los ciudadanos y los poderes e instituciones de la organización política». Ambos significados sintetizan sendas orientaciones con las que «constitución» fue utilizada en el pensamiento político, filosófico y jurídico.

\section{II.3. Brevísima ojeada sobre el recorrido bistórico de «constitución»}

\section{II.3.A. La fuerza normativa de lo fáctico}

El empleo de «constitución» bajo el perímetro del primero de los significados citados - ut supra- da la idea de que todo Estado está constituido; o, si se prefiere, que la organización de la fuerza estatal ha sido llevada a cabo de un modo determinado y específico. Cuando se afirma que determinado Estado está constituido de tal o cual manera, no se está más que efectuando una descripción de la realidad. Bajo esta significación puede predicarse que todo Estado tiene (o ha tenido, según el caso) —indefectiblemente- una constitución concreta. Quizá una de las claves de la distinción radique en la gigantesca distinción que existió entre el concepto de libertad de los antiguos y el concepto de libertad que nace con la filosofía de la Ilustración entre los siglos XVII y XVIII. Libertad tiene múltiples significados; sencillamente, en la aludida distinción se significa, por un lado, «la libertad respecto del Estado»y, por otro, «la libertad del Estado». Al filo de la duda, apoyado en fines ilustrativos y en la célebre cita de Benjamín Constant, me gustaría poder decir que en efecto ha sido cierto que el objetivo eminente de la libertad de los antiguos consistía primordialmente en la distribución del poder 
entre los ciudadanos (la esclavitud era una situación necesaria, tan natural como un curso de agua) de una misma patria; y que, en cambio, en la libertad de los modernos, el objetivo ha sido la seguridad en el disfrute privado de los ciudadanos (la esclavitud seguía existiendo) y, por supuesto, las garantías concedidas para dichos goces ${ }^{7}$.

La afirmación «todo Estado necesita una constitución» es definitivamente verdadera. Porque toda asociación permanente de hombres, para que fuese tal, requiere un principio de ordenación conforme al cual se constituya y desenvuelva su voluntad ${ }^{8}$.

Una veloz ojeada sobre las doctrinas que dominaron el pensamiento jurídico antiguo, medieval y premoderno permite generalizar que el concepto de constitución pertenecía al mundo del ser, y que su significado era de estricta naturaleza descriptiva. Ni en Grecia ni en Roma existieron leyes fundamentales que, bajo el nombre de constitución u otro, hayan expresado por escrito el reconocimiento de los derechos y garantías de los ciudadanos y la organización de las funciones de los poderes estatales, tal como modernamente se lo hace.

En el esquema descripto, el Estado o la ciudad tenían una constitución al igual que el hombre tiene una constitución o complexión física, por ejemplo. La plena existencia del ser, la materia propia y misma. Esta constitución del Estado o de la ciudad era espontánea y natural, no un producto de ningún saber ni tecnología.

Aristóteles en su Política escribió como un maestro de la organización comunitaria, sin conocer su misión magistral, que, por cierto, formaba su presente. Más de 2.300 años después, leamos sus ideas, en las que se anotó rudimentariamente la distinción entre constitución y simple ley:

Un sistema político [una constitución] es una organización [fundamento] de las ciudades relativa a las magistraturas [poderes], a como están repartidas [cómo se ha de dividir el poder], cuál es la autoridad del régimen y cuál es el fin de cada comunidad; las leyes son las que están separadas de los elementos que caracterizan al régimen, y según ellas deben gobernar los magistrados y guardarse de los que las violan?.

7 V. Bobbio, Norberto: Igualdad y libertad, Paidós, Barcelona, 1993, pp. 96-154. Dijo Constant que la libertad de los antiguos comprendía la participación activa y constante en el poder colectivo, mientras que la libertad de los modernos se compone del goce pacífico de la libertad privada. V. Constant, Benjamín: «De la libertad de los antiguos comparada con la libertad de los modernos», en Anuario Jurídico, UNAM, IIJ, 1975, p. 424.

8 Jellinek, Georg: Teoría del Estado, Oxford University Press, México D.F., 1998, p. 302.

9 Aristóteles: Política, Alianza, Madrid, 2007, p. 149 (libro cuarto, I, 1289 a). 
Imposible en esta ojeada describir y releer todas las peripecias del pensamiento, por tomar un punto de partida: desde Aristóteles. Deseo destacar determinados rasgos de determinados pensadores. En cualquier caso: son los pormenores en los que efectivamente se asienta esta ojeada que, en sí misma, es una declaración de autor. No es, entonces, un alfabeto provisional de las historias de las ideas sobre la constitución estatal.

Dos mil años después de las ideas de Aristóteles, Leviatán. O la materia, forma y poder de una república eclesiástica y civil, publicada en 1651 (en adelante, Leviatán 1651), se convierte en una de las primeras obras sobre teoría del Estado; concretamente: el Estado absoluto.

Thomas Hobbes, su autor, por derecho propio, fue el inventor de las ideas absolutistas. Sugirió, sin fisuras, que la naturaleza hizo a los hombres tan iguales que, durante el tiempo en que vivían sin un poder común que los atemorizase a todos, se hallaban en una guerra de todos contra todos ${ }^{10}$. El Leviatán o Estado es el hombre artificial instituido para la protección y defensa del hombre natural.

Un Estado queda instituido — según Hobbes— cuando una multitud de hombres convienen y pactan, cada uno con cada uno, que a un cierto hombre o asamblea de hombres se le otorga, por mayoría, el derecho de representar a la persona de todos; cada uno de ellos debe autorizar todas las acciones y juicios de ese hombre (artificial), como se lo juzgase oportuno, para asegurar la paz y la defensa común. El temor, pues — según Hobbes—, impulsó decisivamente a los hombres al contrato social. Empero, se trataba de un contrato sumamente peculiar: a) el contrato era suscrito entre los súbditos, no por el soberano; b) ninguno de los súbditos podía ser liberado de su sumisión; c) el poder soberano era el único capaz de eliminar o contener la guerra; ergo, se trataba de un poder absoluto, sin límites ${ }^{11}$.

No hay, en la obra de Hobbes, un estudio preciso sobre la norma constitucional. Sí, es cierto, adelantó que el legislador, en todos los Estados, es sólo el soberano. Y que la ley, en general, no es consejo sino orden, que fue traída al mundo para limitar la libertad de los hombres individuales, de tal modo que no pudieran dañarse sino asistirse unos a otros y mantenerse unidos contra el enemigo común. Observó, además, que nunca pudo comprender, en ningún autor, que se entendía exactamente por ley fundamental. No obstante, estimó que ley fundamental en un Estado era aquella en virtud de la cual, cuando la ley se suprime, el estado decae y queda totalmente arruinado, como una construcción

\footnotetext{
10 Leviatán 1651, XIII, pp. 100/102.

11 Leviatán 1651, Introducción (p. 3) y pp. 142-150.
} 
cuyos cimientos se destruyen. Ley fundamental, por tanto, es aquella por la cual los súbditos están obligados a mantener cualquier poder que se dé al soberano, sin el cual el Estado no puede subsistir, por ejemplo: el poder de hacer la paz, la guerra, designar jueces, elegir funcionarios y de «realizar todo aquello que se considere necesario para el bien público». Leyes no fundamentales, según Hobbes, eran aquellas cuya abrogación no lleva consigo la desintegración o desmembramiento del Estado; por ejemplo: las leyes «concernientes a las controversias entre un súbdito y otro» ${ }^{12}$.

\section{II.3.B. Paradigmas normativos}

En la teoría política estatal, que comienza a fraguarse en la modernidad jurídica al calor de los procesos revolucionarios franceses y estadounidenses de finales del siglo XVIII, el significado del término «constitución» se iría trasladando, paulatinamente, al mundo del deber ser, comenzando su metamorfosis hacia su significado de naturaleza prescriptiva o normativa. La idea de la constitución como ley fundamental, rígida, suprema, divisoria del poder fue producto de una lenta evolución histórica y adquirió relevancia y prestigio a la sombra del movimiento filosófico y político que decidió utilizarla para limitar el poder político, intentando garantizar así un espacio a la libertad individual.

Es altamente probable que la redacción del Derecho de una comunidad haya comenzado a ser necesaria cuando este «Derecho era concedido» o había sido objeto de una «confirmación por un poder exterior» ${ }^{13}$. La necesidad de redactar por escrito se vislumbra en las colonias americanas de Inglaterra, en pleno siglo XVII. Contenían, en general, una ideación básica del moderno constitucionalismo: el contrato político, porque en el resto eran concesiones derivadas de un poder superior.

Ineludiblemente, el concepto de constitución se asocia o corresponde ser asociado a la Constitución de Estados Unidos de 1787 y a la Declaración de los Derechos del Hombre y del Ciudadano aprobada en Francia en 1789. Si bien es absolutamente exacto y cierto que habían existido formas jurídico-constitucionales tanto en la Inglaterra del siglo XVII como en las embrionarias formas de organización comunitaria adoptadas, también durante el mismo siglo, por los colonos fundadores de los actuales Estados Unidos, puede afirmarse que el movimiento constitucionalista, cuyas consecuencias normativas e ideológicas conocemos hoy día, empieza a fines del siglo XVIII. Es recién en dicha época

${ }^{12}$ Leviatán 1651, XXVI, pp. 217-237.

13 Jellinek, Georg: Teoría del Estado, Oxford University Press, México D.F., 1998, p. 303. 
cuando son gestados documentos en los que pretende estipularse por escrito las normas a las que debe responder la organización política fundamental y general del Estado, con especificación de los órganos y procedimientos a través de los cuales se debe ejercer el poder racionalmente, así como la relación de tales órganos con las personas y sus derechos ${ }^{14}$.

La Constitución de Estados Unidos fue firmada el 17 de septiembre de 1787. Menos de 4.500 palabras repartidas, con discreción y prolijidad, en un preámbulo y siete artículos. Omnipresente la idea de constitución, como si se tratase de un propio designio del poder constituyente. «Constitución [constitution]», pues, se lee, por ejemplo, en el preámbulo: «We the People (...) do ordain and establish this Constitution...»; en el artículo I, sección 8 (18): «... and all other Powers vested by this Constitution...»; en el artículo II, sección 1 (5): «... at the time of the adoption of this Constitution...»; en el artículo III, sección 2: "The judicial Power shall extend to all Cases, in Law and Equity, arising under this Constitution...»; en el artículo IV, sección 3 (2): «... and nothing in this Constitution...»; en el artículo V: "The Congress, whenever two thirds of both Houses shall deem it necessary, shall propose Amendments to this Constitution...»; en el artículo VI: "All Debts contracted and Engagements entered into, before the Adoption of this Constitution...»; y en el artículo VII: "The ratification of the Conventions of nine States, shall be sufficient for the establishment of this Constitution between the States so ratifying the Same...».

La Declaración de los Derechos del Hombre y del Ciudadano, creada por la Asamblea Nacional francesa, en agosto de 1789, es un texto de menos de mil palabras. La idea de constitución es mentada en el famoso y celebrado artículo XVI:

Toda Sociedad en la que la garantía de los Derechos no esté asegurada, ni la separación de poderes definida, no tiene Constitución.

\section{II.3.B bis. Interludio: las utopías de Thomas Paine}

Los hechos memorables deberían tener siempre fechas memorables que permitan su mención o cita cabal. Los hechos que concretaron la efectiva formulación de la concepción normativa de constitución fueron y son una sucesión de acontecimientos. Se trata de hechos absolutamente significativos. Sería absolutamente

${ }^{14}$ Antonio Torres del Moral escribe inteligentemente: la concepción normativa de la constitución es ilustrada y francesa. Pero fue en Estados Unidos donde se construyó jurídicamente con solidez. La Constitución de 1787 se llama a si misma «Derecho supremo de la tierra» y declara la vinculación de los jueces a ella por encima de las constituciones y de las leyes de los Estados miembros. V. Torres del Moral, Antonio: Principios de Derecho constitucional español, t. I, p. 100, Universidad Complutense de Madrid, 2004. 
insensato atribuir la invención, pura y simple, a la actividad de una persona o de un grupo de ellas. Con certeza, como se desliza letras más atrás, la Constitución de Estados Unidos de 1787, al mantener su vigencia desde entonces, daría pie para sugerir que su importancia es semejante — por su influencia en las constituciones de los siglos XIX y XX - a la determinación ejercida en las ciencias de la naturaleza por la teoría de la relatividad de Albert Einstein o la teoría heliocéntrica de Nicolás Copérnico. La concepción de la constitución como norma sobre normas es un proceso, antes que un único y espectacular suceso en el recorrido de los hombres, en el que han coincidido muchos y variados actores: políticos, filósofos, científicos, juristas, artistas, economistas, religiosos y, principalmente, ciudadanos.

No es mi deseo descorazonar a nadie. No se está en condiciones de fijar un momento original, un punto 0 una fecha de partida de nacimiento de la concepción normativa de constitución. A riesgo de cometer un error, con fines casi exclusivamente literarios, mencionaré a Thomas Paine: uno de los ideólogos de la doctrina de la independencia de Estados Unidos y de su constitución.

Thomas Paine nació en 1737 y falleció en 1809. Participó en la Revolución americana y en la Revolución francesa. Sus intereses fueron múltiples (pensador, diseñador, escritor, político) y su formación fue básicamente autodidacta. Su primer trabajo, African Slavery in America, fue publicado en 1775; un año después, El sentido común. Dirigido a los habitantes de América ${ }^{15}$ (en adelante, SC 1776), y en 1791-1792, Derechos del Hombre. Respuesta al ataque realizado por el Sr. Burke contra la Revolución francesa ${ }^{16}$.

El 4 de julio de 1776 el Congreso continental aprobó la Declaración de la independencia de Estados Unidos. Unos meses antes, Paine publicó su ensayo SC 1776, en el que afirma, con serenidad y simplicidad:

En América la ley es el rey. Pues así como en los gobiernos absolutos el rey es la ley, así en los países libres la ley debe ser el rey, y no deberá haber otro ${ }^{17}$.

Paine tenía profundas convicciones racionalistas. Pensó que tener gobierno propio era una cuestión de derecho natural y que la ciencia de la política consistía en hallar el punto medio entre la felicidad y la libertad.

Desconfiaba de la incertidumbre que provocaba la costumbre en los asuntos humanos. Fundado en la razón, sostuvo:

\footnotetext{
15 Paine, Thomas: El sentido común y otros escritos, Tecnos, Madrid, 1990.

16 Paine, Thomas: Derechos del Hombre. Respuesta al ataque realizado por el Sr. Burke contra la Revolución francesa, Alianza, Madrid, 1984.

17 Paine, Thomas: El sentido común..., ob. cit., p. 42.
} 
Es infinitamente más prudente y seguro formar una Constitución nuestra de una manera tranquila y deliberada, mientras podamos hacerlo, que confiar tan importante acontecimiento al tiempo y la suerte ${ }^{18}$.

¿Quiénes eran los hacedores o forjadores del destino comunitario? Dijo en forma terminante, y casi con seguridad, por primera vez en la historia del constitucionalismo:

Nunca ha existido, nunca existirá y nunca puede existir un parlamento, ni una categoría de hombres, en ningún país, en posesión del derecho de vincular y controlar a la posteridad hasta el fin de los tiempos (...) Cada edad y cada generación deben tener tanta libertad para actuar por sí mismas en todos los casos como las edades y las generaciones que las precedieron ${ }^{19}$.

¿Qué era una constitución para Paine?

La constitución de un país no es acto de un gobierno, sino del pueblo que constituye su gobierno. Es el cuerpo de elementos al que cabe remitirse y citar artículo por artículo, y que contiene (...) los principios en los que se ha de establecer el gobierno, la forma en que se organizará éste, los poderes que tendrá, la forma de las elecciones, la duración del parlamento (...), en fin, todo lo relacionado con la organización completa de un gobierno civil, y los principios en los que se basará y por los que se regiráa ${ }^{20}$.

La constitución para Paine significó «un orden racional de las cosas». Pedagogo de la organización constitucional fundada en la libertad, individual y soberana. Sobre la igualdad, aunque no fue un socialista de pura cepa, llegó a plantear en su obra ciertos modos de «asistencia y redistribución de la riqueza» ${ }^{21}$. Sus pensamientos basados en el iusnaturalismo racionalista constituyen un fundamento del constitucionalismo moderno. Postuló la constitución como primer elemento; naturalmente, no fue un normativista, pero propugnó la constitucionalidad con firmeza.

\section{II.3.C. La hoja de papel}

Sin embargo, a poco de nacer, el significado mismo del concepto de constitución escrita afrontó su primera crisis vital. El 16 de abril de 1862, en circunstancias en que Ferdinand Lassalle pronunció una conferencia sobre la naturaleza

18 Ídem, p. 42.

19 Paine, Thomas: Derechos del hombre..., ob. cit., p. 37.

20 Ídem, p. 68.

${ }^{21}$ V. Paine, Thomas: Derechos del hombre..., ob. cit., p. 254. 
de la constitución ${ }^{22}$. Su tesis básica consistió en exponer que las cuestiones constitucionales no son primordialmente jurídicas, sino cuestiones de poder, porque la verdadera constitución de un país la integran y sólo reside en los factores reales y efectivos de poder que en ese país rigen; y las constituciones escritas no tienen valor ni son duraderas más que cuando dan expresión fiel a los factores de poder imperantes en la realidad social. Opinó Lassalle que la esencia de la constitución de un Estado era igual a la suma de los factores de poder que rigen en ese país: a) un rey, a quien obedecen el ejército y los cañones, es un fragmento de la constitución; pero también lo son: b) el poder militar, representado por el ejército; c) el poder social, representado en la influencia de los grandes terratenientes; d) el poder económico, representado en la gran industria y el gran capital; e) aunque no equiparable a los otros poderes, el poder espiritual, representado en la conciencia y la cultura general; y, finalmente, en ciertos casos extremos y desesperados, f) la clase obrera y la pequeña burguesía, hasta cierto limitado punto.

Lassalle se preguntó qué relación guardaba lo expuesto con lo que vulgarmente se conocía como constitución escrita o jurídica. Respondió:

Se toman estos factores reales de poder, se extienden en una hoja de papel, se les da expresión escrita, y a partir de ese momento, incorporados a un papel ya no son simples factores reales de poder, sino que se han erigido en Derecho, en instituciones jurídicas, y quien atente contra ellos, atenta contra la ley y es castigado ${ }^{23}$.

Para Lassalle, las relaciones efectivamente resultantes del funcionamiento combinado de estos factores representan la fuerza realmente operativa que condiciona de tal modo todas las leyes e instituciones jurídicas de la sociedad que, sustancialmente, no pueden ser de otra manera de como son; se trata, pues, de la constitución real del país. De nada sirve lo que se escriba en una hoja de papel, si no se ajusta a la realidad, a los factores efectivos y reales de poder ${ }^{24}$. La constitución jurídica sólo es, en palabras de Lassalle, un trozo de papel. La aptitud de la constitución jurídica para interpretar o motivar conductas, es decir, su capacidad para la regulación de la vida comunitaria y la organización fundamental de la fuerza estatal, valdría hasta su coincidencia con las prescripciones de la constitución real. Los desajustes entre texto constitucional y la realidad producían un conflicto en el cual, finalmente, la simple hoja de papel terminaba claudicando ante las efectivas relaciones de poder existentes en el Estado.

${ }^{22}$ Lassalle, Ferdinand: ¿Qué es una Constitución?, Ediciones Siglo Veinte, Buenos Aires, 1987, pp. 35-71.

${ }^{23}$ Cfr. Lassalle, Ferdinand, ob. cit., p. 48.

${ }^{24}$ Cfr. Lassalle, Ferdinand, ob. cit., p. 68. 
Sus conclusiones fueron éstas:

Si no olvidan ustedes esta conferencia, señores, y vuelven a verse alguna vez en el trance de tener que darse a sí mismos una constitución, espero que ya sabrán ustedes cómo se hacen estas cosas, y que no se limitarán a extender y firmar una hoja de papel, dejando intactas las fuerzas reales que mandan en el país ${ }^{25}$.

\section{II.3.D. En oposición a Carl Schmitt}

El concepto de constitución en Carl Schmitt se desprende, al menos, de tres de sus obras: a) Concepto de lo político ${ }^{26}$, publicada originariamente en agosto de 1927 bajo forma de artículo y en 1932 bajo forma de libro, en cuyo epílogo el autor dice que no hay nada que sea una «modificación o prolongación» del pensamiento original desarrollado (en adelante, Concepto 1927); b) Teoría de la constitución $^{27}$, publicada en 1928 (en adelante, Teoría 1928) y c) La defensa de la constitución $^{28}$, publicada originariamente en marzo de 1929 en forma de artículo y ampliada bajo la forma de libro en 1931 (en adelante, Defensa 1931). Schmitt fue una persona que vivió casi cien años; la producción citada fue escrita en el período de su madurez biológica, si ha de ser cierto que alguna vez la tuvo. No se sostiene la idea de que exista una articulación lógica ni histórica en los planteos de las tres obras aludidas. Suelen presentarse en la literatura jurídica los cuatro conceptos de constitución planteados por Schmitt, en su Teoría 1928 (ver abajo número viii). No pienso que dicho modo de obrar constituya un error. Simplemente es relevante observar que las «decisiones» escritas por Schmitt en su obra Concepto 1927, sin dudas, marcan el horizonte de proyección de todo lo que escribió después en las otras dos. Sus letras no son el punto de partida sino, rotundamente, el plan de vuelo.

Fundado en razones pedagógicas, y en consonancia con el título de este parágrafo, se construye un decálogo de proposiciones schmittianas, escogidas de sus obras. La elección, por supuesto - hay que decirlo-, se corresponde con un criterio del autor de estas letras. No obstante, por tratarse de un ejercicio académico, obraré del siguiente modo. Se presenta la tesis de Schmitt; sus proposiciones sobre la política, el Derecho, la constitución y su defensa. Inmediatamente, el lector tendrá que conjeturar que mis ideas son exactamente las opuestas; no se realiza, por tanto, una refutación explícita porque ello implicaría escribir una obra misma y desbordaría por completo las ambiciones planteadas ut supra;

\footnotetext{
${ }^{25}$ Lassalle, Ferdinand, ob. cit., pp. 70-71.

26 Schmitt, Carl: Concepto de lo político, Struhart y Cía, Buenos Aires, 2002.

27 Schmitt, Carl: Teoría de la constitución, Alianza, Madrid, 1992.

${ }^{28}$ Schmitt, Carl: La defensa de la constitución, Tecnos, Madrid, 1983.
} 
tarea, además, cuyo primer recorrido consistiría en inventariar la bibliografía ${ }^{29}$ producida sobre la propia obra de Schmitt. Por ende, a continuación de cada proposición schmittiana (y la indicación de su fuente), elaboradas con bastante apego a su presentación textual, me limito a insinuar el término correlativamente opuesto y contrario, cuyo significado yace en mis ideas.

(i) Un mundo definitivamente pacificado sería un mundo sin la distinción del amigo y el enemigo, y, por tanto, un mundo sin política. El Estado dispone abiertamente de la vida de los hombres. (Concepto 1927). (Paz y soberanía personal).

(ii) La distinción propiamente política es la distinción entre amigo y enemigo (Concepto 1927). (Tolerancia).

(iii) Los pueblos se agrupan en función del antagonismo amigo-enemigo (Concepto 1927). (Coexistencia).

(iv) La esencia de la unidad política consiste en suprimir el antagonismo dentro de la unidad. Enemigo es una totalidad de hombres situada frente a otra análoga que lucha por su existencia. Con el enemigo existen conflictos existenciales que no pueden resolverse con normas generales preestablecidas ni por el fallo de un tercero no partícipe y, por consiguiente, imparcial (Concepto 1927). (Debate y crítica racional).

(v) La significación de los términos Derecho, orden y paz está concretamente determinada por el enemigo. Un mundo pacificado, sin guerra, sería un mundo sin política por la ausencia de distinción entre amigo y enemigo. El Estado es una unidad decisiva por su carácter político. (Concepto 1927). (Pluralismo).

(vi) Jamás podrá existir un Estado mundial que abarque la humanidad entera, porque la unidad política presupone la posibilidad real del enemigo. La unidad política, por razón de su esencia, será universal en el sentido que abrazará a toda la humanidad y la tierra entera. (Concepto 1927). (Ciudadanía universal).

(vii) Schmitt atribuyó cuatro sentidos al concepto de constitución: absoluto, relativo, ideal y positivo (Teoría 1928). (Un solo sentido: constitución).

(viii) Un concepto de constitución sólo es posible cuando se distinguen constitución y ley fundamental. La esencia de una constitución no está contenida en una norma. La constitución en sentido positivo surge mediante un acto del poder constituyente. El acto constituyente no contiene como tal unas normas cualesquiera, sino, y precisamente por un único momento de decisión, la totalidad de la unidad política considerada en su particular forma

29 Recientemente, Daniel Rafecas publicó: «La ciencia del Derecho y el advenimiento del nazismo: el perturbador ejemplo de Carl Schmitt», en Revista Academia, $\mathrm{n}^{\circ} 15$, Facultad de Derecho, 2010, pp. 133-163. 
de existencia. Este acto constituye la forma y modo de la unidad política, cuya existencia es anterior. La normación constitucional presupone una voluntad como existente. La constitución en sentido positivo contiene la determinación consciente de la concreta forma de conjunto por la cual se pronuncia o decide la unidad política. Esta forma se puede cambiar. Se puede introducir nuevas formas sin que el Estado, es decir, la unidad política del pueblo, cese. Que una constitución se dé a sí misma es un absurdo manifiesto, porque la constitución vale por virtud de la voluntad política existencial de aquél que la da. (Teoría 1928). (Naturaleza y convención comunitaria: normativismo).

(ix) En el fondo de toda normación reside una decisión política del titular del poder constituyente. (Teoría 1928). (Diálogo, experiencia y libertad).

(x) En toda decisión, incluso en la de un Tribunal de Justicia que en forma procesal realiza subsunciones de tipo concreto, existe un elemento de pura «decisión» que no puede ser derivado del contenido de la norma. Schmitt propone para dicho elemento la denominación de decisionismo. La decisión sobre la protección de la constitución tiene que corresponder al Presidente del Reich. (Defensa 1931). (Democracia y razón).

Por imperativo literario, niego el valor de verdad de cada una de las diez proposiciones schmittianas. Introduzco e induzco hacia ellas la oposición por contrariedad $^{30}$ : dos proposiciones son contrarias si no pueden ser ambas verdaderas al mismo tiempo, al distar entre sí al máximo dentro del mismo género, aunque puede resultar que ambas encierren una falsedad. Al descalificar, como hago, todas y cada una de las proposiciones de Schmitt, se asume que mis negaciones eliminan la posible verdad de las de él. No obstante, la expresión de mi contrariedad no alcanzará a cubrir que las schmittianas y las mías puedan ser ambas, en forma semejante, también falsas. Sería necesario, en la hipótesis, la generación de un tertium datur (tercer dato o tercera proposición). Mientras tanto, en desacuerdo total con Schmitt, mantengo la microtesis en el ámbito de la «conjura» descrita por el poeta mayor argentino: «la extraña resolución de ser razonable» ${ }^{31}$.

La propiedad mayor de una «sociedad cerrada» reside, precisamente, en que su «vida transcurre dentro de un círculo de normas y costumbres que se reputan tan inevitables como las evidentes uniformidades de la naturaleza» ${ }^{32}$. Lo que Schmitt denominó «decisión», y tras de él, la literatura, «decisionis-

30 V. Copi, Irving: Introducción a la Lógica, Eudeba, Buenos Aires, 1999, pp. 176-179. Aristóteles: Categorías, Colihue, Buenos Aires, 2009.

31 Borges, Jorge Luis: Obra poética, «Los conjurados», Emecé, Buenos Aires, 2007, p. 642.

32 Cfr. Popper, Karl R., ob. cit., p. 67. 
mo», es pura actuación del ser, puro hecho, fundado en una voluntad, cuyo marco de referencia o conocimiento escapa a la razón, al sentido común de cualquier ciudadano. Schmitt adhirió al nazismo, planteó y desarrolló la pura existencialidad porque encajó con su desprecio de la dignidad humana, el desmantelamiento de la libertad del ciudadano y de la organización democrática de la comunidad.

\section{II.3.E. La teoría pura del Derecho}

Hans Kelsen fue una persona que dedicó su vida a la filosofía, la sociología y el Derecho; cuenta con cientos de publicaciones en el campo de la producción científica, traducidas a enorme cantidad de lenguas; ejerció como juez y brindó, incansablemente, conferencias y lecciones en Europa y América. Vivió más de noventa años.

Sus puntos de vista sobre la constitución fueron objeto de mención y tratamiento, singular y determinado, en muchas de sus obras; a título de ejemplo: Teoría general del Estado (1925); ¿Quién debe ser el defensor de la Constitución? (1931) y Teoría general del Derecho y del Estado (1945). En las líneas siguientes, servirá de repertorio únicamente su Teoría pura del Derecho (en adelante, TPD 1960); primero, porque, como se declara en la sección I, la finalidad en esta sección II consiste, sustantivamente, en revistar los alineamientos conceptuales en torno a hecho o a norma; segundo, porque no se quita felicidad al lector si se anuncia que Kelsen fue un normativista, y tercero, por el hecho de que la TPD 1960 es la última obra «orgánica» de Kelsen, elaborada poco antes de su muerte en 1973. A veces, el lenguaje encierra fatalidades. Prefiero evitarlas: no se afirma que en la obra citada se encuentra el último pensamiento kelseniano, sino, simplemente, la última y ahora conocida presentación formal de sus ideaciones «orgánicas y sistemáticas» sobre la constitución.

Kelsen creyó que una teoría pura del Derecho no debía ni podía desempeñar ninguna tarea reformadora ni creadora del objeto de estudio: el Derecho. Si lo hacía, excedía su competencia y se convertía en herramienta de la política. Postuló, por eso, un mundo de abstracciones normativas casi geométricas, en el que la tarea del saber o ciencia jurídica se limitaba a describir el objeto, sin estar influenciada o contaminada por la política o su interés. El conocimiento jurídico era un saber dirigido hacia normas. Partía de un dualismo fundamental: naturaleza y sociedad; la ley natural descansa en el principio de causalidad, mientras que la ley social descansa en el principio de imputación creado mediante actos de voluntad de los hombres. 
El Derecho - para Kelsen - era «una ordenación normativa del comportamiento humano»; este «sistema de normas» que regulan o determinan la conducta de los hombres se caracterizó porque sus normas se encontraban «en una construcción escalonada de diversos estratos».

Kelsen opinó que en la observación de un «orden jurídico estatal, el estrato superior jurídico positivo, está representado por la constitución», entendida en sentido material: norma o normas que regulan la producción de las normas jurídicas generales. Constitución, por su parte, que pudo haber sido producida «por vía de la costumbre, o (...) mediante un acto legislativo» ${ }^{33}$.

Kelsen también se ocupó de distinguir la «constitución en sentido material» de la constitución «en sentido formal»; respecto de esta última dijo que se trataba del

... documento denominado «constitución» que, como constitución escrita, no sólo contiene normas que regulan la legislación, esto es, la producción de normas generales, sino también normas que se refieren a otros objetos políticamente importantes, así como disposiciones según las cuales las normas contenidas en ese documento, la ley constitucional, no pueden ser derogadas como simples leyes, sino sólo bajo condiciones más difíciles mediante un procedimiento especial. Estas disposiciones configuran la forma constitución que, como forma, puede recibir cualquier contenido, sirviendo en primer término para estabilizar las normas que aquí designamos como constitución material, y que constituyen el fundamento jurídico positivo de todo orden jurídico estatal ${ }^{34}$.

Renglón seguido advirtió que la producción de normas jurídicas generales, regladas por la constitución material, tiene, dentro de los órdenes jurídicos estatales modernos, el carácter de una legislación. Por eso, la constitución que regula la producción de normas generales podía determinar también el contenido de leyes futuras, y las constituciones positivas lo hacen no poco frecuentemente, al prescribir (promesa de legislación), o excluir ciertos contenidos (impedir o inhibir que ciertas leyes ordinarias devalúen o deterioren las «libertades que son parte integrante de las constituciones modernas» ${ }^{35}$ ).

El aporte de Kelsen a la ciencia jurídica y al Derecho como objeto específico de su estudio ha sido notable. La configuración de la constitución como norma y como norma sobre normas responde a cientos de causas; sería engañoso no considerar la contribución decisiva de Kelsen. Anotó en la dogmática, quizá antes que otros lo hicieren, la jerarquía lógica de la ley fundamental. Dedicó

\footnotetext{
33 Kelsen, Hans: Teoría pura del Derecho, Porrúa, México D.F, 1998, p. 232.

34 Ídem, p. 233.

35 Ídem, p. 234.
} 
una porción importante de sus obras a la defensa de la norma constitucional; su disertación no fue un simulacro, porque postuló abiertamente la necesidad de configurar una garantía jurisdiccional especializada; en la genealogía o historia de la constitución y su defensa, la producción kelseniana constituye un proceso de naturaleza insoslayable por su profundidad y actualidad. Que casi todos los Estados del mundo posean una constitución, actualmente, definan su organización y unidad estatal, con fundamento o arreglo a una constitución, escrita, vinculante, sin magnificar ni abrir cultos, se debe, en parte, a las ideas de Kelsen. Alguien podría afirmar al mismo tiempo su aporte en la protección de la Ley Mayor del sistema, porque hoy también todos los estados tienen o poseen una jurisdicción constitucional. Qué difícil sería desdeñar, también, esta observación.

\section{II.4. Interludio: el trialismo de Germán J. Bidart Campos}

Germán J. Bidart Campos fue uno de los juristas y maestros del Derecho más importante, en la Argentina, durante el siglo XX. Prolífico escritor: su producción comienza en 1953 con La democracia como forma de Estado y se extiende, ininterrumpidamente, hasta 2004 con el Compendio de Derecho constitucional, momentos antes de su muerte. Su obra póstuma es Nociones constitucionales, 2007.

Aproximadamente en 1964 se publicó Derecho constitucional. Realidad, normatividad y justicia, obra desde la que alentó un singular enfoque. Escribió que correspondía encarar o captar el mundo del Derecho constitucional con o desde «tres órdenes» estrechamente relacionados entre sí, pero distinguibles unos de otros: el normativo, el de la realidad existencial y el axiológico. La constitución escrita se encontraba en el orden normativo; también las leyes constitucionales y la normatividad consuetudinaria y espontánea. En el orden de la realidad existencial se hallaba la conducta humana: las personas que ejercitan el poder estatal reparten bienes y males entre las personas que son recipiendarios. El orden axiológico, por su parte, suministraba criterios de valor para juzgar al orden normativo y al orden existencial, respectivamente. Para Bidart Campos, la constitución verdadera consistía en la «conjugación de realidad y deber ser», el ajuste recíproco de la realidad y la norma ${ }^{36}$.

Con fidelidad, Bidart Campos mantuvo su tesis en defensa de esta concepción. En la edición de 1993 de su Tratado elemental de Derecho constitucional argentino, sostuvo que el contenido del Derecho constitucional era más estrecho

${ }^{36}$ Bidart Campos, Germán J.: Derecho constitucional. Realidad, normatividad y justicia, Ediar, Buenos Aires, circa 1964, pp. 11-16; 111-114 y 135-136. 
o más amplio, según la perspectiva que se adoptase; así, si se usaba la del Derecho constitucional formal, el contenido estaba dado exclusivamente por la constitución escrita codificada, su sitio de emanación u origen; si, en cambio, se empleaba la perspectiva del Derecho constitucional material, el contenido se volvía mucho más abundante, porque sin encasillarse en el texto de la constitución formal, al desplazarse hacia el orden existencial, todas las conductas ejemplares y todas las normas descriptivas de ellas (dentro o fuera de la constitución formal, estén formuladas por escrito o no lo estén), resultaban abarcadas. Proponía, entonces, que el derecho constitucional material que emanaba de la constitución material sería siempre «más amplio» que el Derecho constitucional formal, aunque se diese la hipótesis de que la constitución material y la formal coincidiesen ${ }^{37}$.

Finalmente, sin renegar de su enfoque, anunció y desarrolló en $1995^{38}$, y ratificó en la última edición de su Tratado en $2000^{39}$, que el derecho que emana de la constitución formal o escrita era el derecho de la constitución: normativo. Propiamente jurídico. Y que de esta juridicidad que se predicaba de todo el texto constitucional escrito —incluido su preámbulo y sus disposiciones transitorias - se desprendía la fuerza normativa. Por eso, el Derecho que emana de la constitución escrita posee en sí mismo fuerza o vigor normativos, lo que significa que era exigible, obligatorio, aplicable y vinculante: para gobernantes y ciudadanos. Matizó: la fuerza normativa está en las normas del derecho de la constitución que surge de la constitución, pero se dirige «a realizarse» en la dimensión u orden sociológico o existencia de las conductas; o sea: «apunta a alcanzar la efectividad de las normas escritas en la vigencia sociológica».

Por estas razones, Bidart Campos fue un trialista, si se desea sintetizar cuál era su enfoque para describir y valorar el Derecho. El mundo jurídico se compone — como se insinúa arriba— de tres dimensiones u órdenes, y cualquiera que desee conocer el Derecho Constitucional de un Estado no podría conformarse con la lectura de su Constitución escrita. Consecuentemente, según Bidart Campos, para conocer la constitución no bastaba la normatividad emergente del texto escrito; se exigía, además, acudir al examen de su funcionamiento, indagando también qué contenidos constitucionales existen en forma de valores;

37 Bidart Campos, Germán J.: Tratado elemental de Derecho constitucional. El derecho constitucional de la libertad, tomo I, Ediar, Buenos Aires, 1993, pp. 82-99.

38 Bidart Campos, Germán J.: El derecho de la constitución y su fuerza normativa, Ediar, Buenos Aires, 1995.

39 Bidart Campos, Germán J.: Tratado elemental de Derecho constitucional, Ediar, Buenos Aires, 2000, pp. 284-317. 
estado en el cual el investigador podrá encontrar la estimativa o valoración, es decir, la justicia o injusticia del plexo analizado.

\section{SIGNIFICADO DE CONSTITUCIÓN}

El término «constitución» se encuentra impregnado de un importante significado político, como ningún otro de los términos que emplea el Derecho objetivo en el discurso de los juristas y operadores jurídicos. Su sola mención puede ser útil para sugerir, casi inmediatamente, ideas tales como libertad, igualdad y organización de los poderes constituidos; o derechos fundamentales de la persona y su consiguiente garantía, y limitación y control de los poderes constituidos.

La constitución señala un vital y concreto punto de inflexión. Es decir: por un lado, revela y exhibe la finalización del proceso de construcción política del Estado; y por otro, estructura las bases para el arranque y apoyo de todo su edificio jurídico-normativo.

Todas, absolutamente todas las ramas del Derecho positivo en vigor encuentran su último (y su único) fundamento en la constitución. La constitución no es sola e indiscutiblemente el instrumento más importante del Derecho. Significa, además, el fundamental.

Defino, pues, a la constitución como una combinación de normas jurídicas que regulan y determinan el modo en que debe ser ejercido y controlado todo el poder político y, paralelamente, por las que se confiere reconocimiento a los derechos fundamentales de los habitantes. En otras palabras, la constitución como tipo de norma estipula cómo debe ser (no necesariamente cómo es) la estructura jurídica fundamental del Estado.

Las normas de la constitución son el cimiento que sustenta al sistema jurídico del Estado, autónomo o soberano. La noción de la constitución descansa en reconocer que sus finalidades esenciales consisten en: a) proteger y satisfacer los derechos de libertad, los derechos sociales y los derechos de tercera generación; b) estipular los procedimientos que aseguren un ejercicio racional y controlado de los poderes del Estado.

La constitución posee, a mi juicio, un decálogo de propiedades que la singularizan, especifican y entronizan en el sistema. Me refiero, pues, a la primacía, jerarquía, elasticidad, apertura, unidad, coherencia, soberanía, organización, identidad y vinculación de la totalidad de sus enunciados normativos y de los que no lo son, características o propiedades elementales que no se aprecian con simétrica magnitud en el resto de las ramas que componen el sistema jurídico- 
estatal. Por eso, entonces, la constitución del Estado es, antes de todo y por sobre todo, una norma jurídica que, arraigadamente, posee sus especificidades propias.

(i) Primacía. La constitución es el instrumento paradigmático que configura la articulación jurídica del Estado. A la constitución también se la puede definir como un sistema de normas abiertas que expresan el principio de la soberanía de los ciudadanos que integran el pueblo y que concretiza en su texto la correspondiente carta de navegación político-institucional. No existe norma positiva por encima de la constitución.

(ii) Jerarquía. La constitución contiene criterios procedimentales que validan el sistema jurídico subconstitucional. En la norma jurídica constitucional hay una axiología del poder constituyente originario o, si se prefiere, como dice Luigi Ferrajoli, esas «tablas de derecho natural» que, al ser positivizadas en los textos constitucionales, hacen que se modifique de cuajo el viejo criterio de validez del derecho ${ }^{40}$. El hombre inventó la constitución positiva, escrita, codificada, porque descubrió que el Derecho natural no era suficiente marco ni soporte racional. E inventó el escalonamiento o gradación jerárquica de las normas para asegurar que la norma mayor no debe ser reformada con base en los procesos previstos para la creación cotidiana del Derecho ni por las autoridades que ejercen el poder constituido. Por eso es la Ley Mayor, fundamento del Derecho constitucional y éste de todo el Derecho.

(iii) Elasticidad. El Derecho y el Estado son dos entes artificiales o convencionales cuyos propósitos específicos — valga el aparente contrasentidoconstituyen un medio: asegurar la vida y la dignidad, y proteger y satisfacer los demás derechos fundamentales de las personas que componen la sociedad. El plan básico, nuclear y fundamental para cumplir tales propósitos es la constitución del Estado, la que en el interior de sus paredes jurídicas recepciona una importante gama de valores comunitarios, acerca de los cuales es factible suponer la existencia de un importante consenso a su respecto. Dichos valores, al ser positivizados, ponen al descubierto el tránsito desde una categoría axiológica a otra deontológica, manifestando su juridificación, o, en otras palabras: en este tránsito se pone en evidencia que las valoraciones iusfundamentales comunitarias dejan de ser valores y pasan a ser, en la mayoría de los casos, derechos fundamentales. Esta inserción jurídica-normativa en el programa constitucional de los lineamientos provenientes de las valoraciones iusfundamentales comunitarias sirve o es útil para indicar cuáles serían las razones de derecho constitucional, es decir, determina qué es lo que se ordenaría mandar jurídico-normativamente en un Estado. Estas razones jurídico-constitucionales tienen una dimensión de

${ }^{40}$ Ferrajoli, Luigi: Derecho y razón. Teoría del garantismo penal, Trotta, Madrid, 1997, p. 357. 
neto corte procedimental y no ideológico, porque no constituyen ningún plan de ética privada para serles impuesto a los seres humanos de la comunidad, dado que cada uno de ellos por definición siempre tiene asegurado su libre albedrío respecto de la adopción de sus decisiones personales. Constituyen líneas de acción para el ejercicio de la fuerza estatal extremadamente elásticas, porque deben cubrir el paso de una generación a otra.

(iv) Apertura. No es fácil ni tarea sencilla comprobar la completa coincidencia entre constitución y realidad política. Pero ello no implica renunciar de antemano a la posibilidad de que la norma de normas pueda concretar su realización. En todo caso, la efectiva normatividad de las reglas constitucionales depende, en primer lugar, de la conexión que ellas tengan con la realidad política que pretende reglar. Cuanto más importante sea el grado de ignorancia que las normas constitucionales tengan sobre la realidad a la que pretende ajustar o reglar o dirigir por intermedio de sus disposiciones, más intensa será la caída libre de la fuerza normativa de sus enunciados. El estado constitucional de Derecho puede ser justificado como el resultado de cierto marco consensual entre los integrantes de una comunidad, los ciudadanos, en un principio libres, que acuerdan expresar los vínculos estrictamente necesarios y mínimos para el desenvolvimiento de la coexistencia pacífica y perdurable. La constitución es el instrumento que contiene la expresión del consenso puesto de manifiesto por los contrayentes. La constitución es un gran contrato, una representación de la realidad política comunitaria. Las principales reglas de este megacontrato son los derechos fundamentales, cuyo reconocimiento, según el caso, los textos constitucionales confieren a los individuos, a los grupos de personas o a la colectividad o comunidad, respectivamente.

Pienso que la tarea que debe asignarse a los poderes constituidos es concretar y respetar tales inscripciones iusfundamentales. No se desconoce que la constitución debería estar vinculada al tiempo y a la realidad a la que se enfilan sus prescripciones, ya que precisamente esa realidad a la cual se dirigen sus disposiciones normativas está sujeta al devenir y al cambio histórico. Y si ante múltiples y cambiantes circunstancias históricas la constitución pretende resguardar su fuerza normativa sin alterar su propia identidad, el único modo posible de hacerlo es a través de su concepción como norma abierta, sobre todo en el sector normativo dedicado a los derechos fundamentales, dado que con todo rigor debe de aceptarse que el desarrollo progresivo de los mismos es la clave de su conceptualización.

La apertura postulada para la interpretación de la textura constitucional también se impone para su modificación o cambio. Los ciudadanos que integran el pueblo, el único soberano, son los que tienen derecho a cambiarla cuando en libre deliberación se determine que es oportuno y necesario disponerlo. Por eso 
es preferible pensar en reformar la constitución toda vez que se pueda determinar que ello sea necesario, conveniente y oportuno, y no deformarla mediante interpretaciones que la vuelven sin sentido, desnaturalizando (según los casos, de modo parcial o completo) las pretensiones de normatividad emergentes de sus disposiciones. El consenso para cambiar la constitución no es ni uniformidad ni unanimidad; se trata, en cualquier caso de respeto al proceso reglado, de obligada consulta y participación del cuerpo electoral y clara determinación de los contenidos a ser cambiados.

En tales condiciones, la constitución jurídica expresa, a no dudarlo, la tensa relación que se genera entre el mundo del ser y el mundo del deber ser. Alcanzar el punto de equilibrio entre la realidad social y el modo en que ella debiera ser, según indican y ordenan las prescripciones constitucionales, es la tarea más importante de este fenomenal instrumento de la modernidad jurídica: la constitución. Al fin y al cabo, ella fija — ni más ni menos- el perímetro jurídico en cuyo interior debe desplegarse íntegramente el desenvolvimiento racional, equilibrado, controlado y responsable de los poderes del Estado, y el reconocimiento y satisfacción de los derechos fundamentales de los habitantes.

El reconocimiento de la constitución como norma jurídica supone la configuración de una herramienta para el control, y consiguiente limitación del poder.

Las sociedades mágicas o tribales son cerradas porque se basan en la tradición. Una sociedad abierta es aquella en la que los ciudadanos adoptan, porque se les garantiza adoptar, todas sus decisiones personales.

Constitución abierta es sinónimo de apertura constitucional. Pretendo enlazar la misma idea, ora como adjetivo, ora como sustantivo y viceversa. En consecuencia, se desenvuelve en un triple sentido: a) un contrato entre ciudadanos, abierto y plural; b) la posibilidad de que el contrato sea actualizado, y, especialmente, c) que la contratación política se funde en la razón.

(v) Unidad. El sistema jurídico posee una estructura jerárquica en la que, comenzando por la base, cada uno de los enunciados que expresan normas inferiores (subconstitucionales) encuentra su fundamento de validez en la norma superior, hasta llegar a la norma jurídica suprema del sistema: la constitución. Dado que la constitución jurídica del Estado programa las formas y procedimientos para la elaboración y ulterior legitimación de toda la producción jurídica subconstitucional, puede advertirse que, en cierta medida, las normas que componen esta última reciben o hallan en la constitución la garantía para su validación formal y material. La coactividad de todas las normas del sistema jurídico, es decir, la posibilidad concreta de su imposición por la fuerza para el hipotético caso que sus contenidos no sean satisfechos espontáneamente por la población, se encuentra garantizada —al menos en el plano teórico 
descriptivo- por la constitución. En consecuencia, la unidad que se predica de la constitución implica que la totalidad ordenada que ella constituye habilita a que todas las demás normas del sistema remonten o puedan remontar su validez, formal y material, a ella.

(vi) La coherencia. Dos o más enunciados son coherentes cuando puede decirse que son compatibles. Las normas no tienen valores de verdad porque son, en líneas generales, determinaciones o regulaciones prescriptivas. Es imaginable, por supuesto, que pueda existir constitucionalmente una norma que regula una conducta y la autorice y, en paralelo, en la misma constitución otra norma que prohíba la misma determinación de la conducta humana que había sido autorizada. Naturalmente, aunque insensato, puede ocurrir. En consecuencia, la contradicción (del ejemplo citado) será, con exactitud, entre los contenidos de las normas, no entre las normas ${ }^{41}$.

La compatibilidad o coherencia, además, expresa una conformidad general a una regla o patrón que se desempeña como criterio de los criterios; en nuestro caso, aunar, constantemente, el juego de la libertad con el ejercicio del poder; en otras palabras, soberanía individual y autoridad comunitaria.

La coherencia es una cualidad inmensamente relevante, porque la existencia de enunciados contradictorios implica arbitrariedad. Y la constitución tiene que ser el código de la racionalidad ciudadana.

Una constitución combina gran cantidad de normas y enunciados que se refieren a los derechos fundamentales, al poder, a la reforma o a simples declaraciones. Frente a dicha combinación, desde el punto de vista teórico, es imaginable pensar que todas las normas tienen semejante cotización o que poseen cotización diferenciada. Cotizar, valuar normativamente el material de la constitución, es el único modo racional de plantear y desarrollar la coherencia de la constitución.

La última respuesta, siempre, la tiene el poder constituyente, el redactor de la constitución. Si el redactor no estipuló ni fijó una cotización diferenciada entre los enunciados, los realizadores de la constitución tendrán que cotizar todas las normas por igual, con idéntica cotización. Si, por el contrario, el redactor de la constitución fijó diferentes cotizaciones, tendrá que estarse a ellas.

En el caso particular de la CFA, por ejemplo, no hay cotización interna entre sus propias normas; ergo, la coherencia se mantiene en la realización, a condición de que se entienda que una norma no anula ni desvirtúa a otra norma. La compatibilidad, seguida de la complementación normativa, es el secreto que se presenta con voz propia, para respaldar la armonía y coherencia de las normas constitucionales. Coherentemente: todas las normas que emanan de la CFA co-

${ }^{41}$ Von Wright, George Henrik: «Ser y deber ser», en Aulis Aarnio, Ernesto Garzón Valdés y Jyrki Uusitalo (compil.): La normatividad del Derecho, Gedisa, Barcelona, 1997, p. 97. 
tizan por igual. Y en caso de que se advierta una frustración o contradicción, el intérprete tiene la obligación de agotar los esfuerzos a su alcance para alcanzar la armonía que las compatibilice.

(vii) La soberanía, en sentido semejante al de la autoridad jurídica suprema. Hay dos soberanías que la constitución tiene que articular: la individual y la comunitaria. La soberanía del ciudadano es anterior al pacto original; quien nada posee no puede, porque no tiene sobre qué pactar. El poder del Estado, precisamente, tiene por finalidad dar seguridad a aquella soberanía individual.

La persona humana es su propia autoridad jurídica que realiza una competencia suprema. Reconocer, además, la soberanía del Estado significa descubrir que dicho ente no obedece a ningún otro ente. Por su parte, pensar en limitaciones jurídicas a la noción de soberanía no es una contradictio in terminis y no implica un regreso al infinito, porque todos los actos fuera de la competencia suprema no podrían ser observados como soberanos ${ }^{42}$. El artículo 19 constitucional delimita el campo de la soberanía personal de cada individuo. Constituye un límite, fijo, definitivo, infranqueable. La misma regla, junto con artículo 1 y el 33, dibujan el mapa de la soberanía estatal. Nace la constitución, con sus normas soberanas, siempre a disposición de los hombres. Porque es cierto que un sistema jurídico se autorregula, pero para evitar perplejidades, bajo el dominio humano; jamás al revés.

(viii) Organización. Dar forma a una realidad política es la luz que irradia la constitución. La constitución no es obra de artífices sapientísimos. Tampoco resultado de una obra irrepetible. Es, como cualquier instrumento humano, perfectible. Un sistema jurídico fundamental, obviamente, también será necesario para mantener y desarrollar la formación que origina la constitución ${ }^{43}$. La arquitectura del Estado, cuya normación fundamental hace la constitución, no es eterna, porque ningún conjunto de hombres ni ningún órgano tiene competencia suprema o autoridad para hacerlo. La organización consiste en posibilitar racionalmente las acciones objetivas, en campos determinados y delimitados, para que desarrollen las tareas eminentes de legislación, administración y jurisdicción. Funciones jurídicas básicas, al servicio del hombre y su calidad de vida.

(ix) Identidad. Volvamos nuestra mirada a la sección I: la naturaleza es fruto de la evolución; la cultura, fruto del creación humana. Es un mérito de Peter

${ }^{42}$ V. Garzón Valdés, Ernesto: «Acerca de las limitaciones jurídicas del soberano», en AA.VV., El lenguaje del Derecho. Homenaje a Genaro R. Carrio, Abeledo Perrot, Buenos Aires, 1983, p. 179.

43 V. Hesse, Konrad: «Constitución y Derecho constitucional», en AA.VV., Manual de Derecho constitucional, Marcial Pons, Madrid, 1996, pp. 1-15. 
Häberle el planteo de una nueva tesis de partida: la constitución como cultura. El profesor alemán señala:

La constitución no es solamente un texto jurídico ni tampoco una acumulación de normas superiores, es también expresión de un estado de desarrollo cultural, un medio de autorepresentación de un pueblo, un espejo de su herencia cultural y un fundamento de sus nuevas esperanzas. Las constituciones vivas son la obra de todos los intérpretes [realizadores] de la sociedad abierta... ${ }^{44}$

La constitución, al captar la supremacía de la ciudadanía insertada en un Estado obligado a su respeto y promoción, pone al descubierto por completo la identidad comunitaria. La constitución posee normas de adaptación y normas de estímulo. Por las primeras, da cobertura a la realidad que la antecede y que se dispone a cobijar en tiempo presente. Por las segundas, trata de proponer, de modo ideal, una realidad que prometedoramente puede cumplirse. La comprensión más acabada o inacabada de ambos tipos de normas permite distinguir, con bastante certeza, el grado de cultura alcanzado por un pueblo; en concreto, su identidad con relación a la vida, al ambiente, las ciencias y las artes.

(x) Vinculación. ¿Quién y cómo garantiza el cumplimiento de los principios y reglas estipuladas por la constitución? La concepción misma de la fuerza normativa de la constitución, y la natural efectividad que ella conlleva, exige a su vez la existencia de garantías que aseguren eficazmente su cumplimiento, ya que la peculiaridad de la norma constitucional, es decir, su posición jerárquica y privilegiada en el sistema normativo estatal, la obliga a garantizarse por sí misma.

Si la constitución no tuviera garantías, no sólo se obstaculizarían sus planes de concretización y realización político-jurídicos. Una tarea es redactar una constitución. Otra tan imprescindible es brindarle racionalidad al cumplimiento posible de sus prescripciones. Para cumplir tal cometido, se hace necesario elaborar mecanismos aptos para proteger y defender su normatividad, residiendo en las garantías los procesos capaces de viabilizar las pretensiones de vigencia de la constitución.

Coherente con la sistemática presentada ut supra, se invita entonces al examen de la composición de la constitución en la próxima sección. Luego, en la sección $\mathrm{V}$, será el turno de la descripción del mecanismo auroral que proporcionan las garantías.

${ }^{44}$ Häberle, Peter: «La constitución como cultura», Anuario Iberoamericano de Justicia Constitucional, n 6, CEPC, Madrid, 2002, pp. 177-198. 


\section{LAS PARTES}

\section{IV.1. Presentación básica}

Mencionar las partes y descubrir las garantías resulta un paso significativo para penetrar, ulteriormente, en el conocimiento cabal del Derecho de la constitución o Derecho constitucional. Todo el Derecho constitucional fluye de la constitución; recuérdese que, en el caso de la Argentina, su Ley fundamental federal es la fuente de producción de las normas, permanentes y transitorias, de raíz constitucional que emanan de las cuatro esquinas de su texto; fuera de su texto, al mismo tiempo, por aplicación del artículo 75, inciso 22 constitucional (producido por el poder constituyente en 1994), la Constitución es fuente de aplicación y validación de los DDHH que gozan de jerarquía constitucional. En consecuencia: existe un Derecho constitucional federal de la Argentina de raíz y jerarquía constitucional (primer subsistema); existe también un segundo subsistema que no tiene raíz constitucional, pero sí jerarquía: los DDHH validados jerárquicamente por el artículo 75, inciso 22, recién referido. Además, también tiene existencia una hipótesis singular y excepcional de creación que no es tratada aquí: la interpretación judicial, especialmente de la Corte Suprema de Justicia de la Nación (CSJN) al asociar un significado y crear Derecho constitucional $^{45}$. Así resulta inaugurado el «sistema de la Constitución federal», que queda integrado por los tres elementos antedichos: las normas propiamente formuladas en la CF; las normas provenientes de los DDHH y las normas generadas por la CSJN. No obstante, aunque propiamente se trata del «sistema de la Constitución federal», por economía de palabras y no otra razón, se apela únicamente al término «Constitución federal» o constitución, simplemente, tal como se anuncia en el último párrafo de la sección I.

En consecuencia, se examinan las partes de la constitución, especial y casi exclusivamente en foco: la Constitución federal de la Argentina. El examen de las partes, naturalmente, no dice ni puede afirmar o describir o ponderar todo lo que se desea saber sobre el objeto, sino tan sólo su composición. Luego, más adelante, en la sección IV, se examinan las relaciones internas entre los propios componentes o partes, es decir, el análisis estructural, basado en los procesos internos que autorizan un regular funcionamiento de sus partes. Me refiero, concretamente, a las garantías.

${ }^{45}$ Sobre la interpretación judicial, puede leerse Ferreyra, Raúl Gustavo: «Rasgos básicos del derecho constitucional: sistema; libertad, igualdad, solidaridad; teoría», en Revista de Derecho Político, nos. 75-76, Universidad Nacional a Distancia, Madrid, 2009, pp. 215-242. 


\section{IV.2. Composición estricta}

Una sencilla y primera lectura de la CFA — actualmente vigente, según texto de 1853-1960, con sus reformas producidas en 1866, 1898, 1957 y 1994-, vale para comprobar las siguientes piezas desplegadas en partes, claramente definidas por la creación constituyente:

(i) Preámbulo ${ }^{46}$

(ii) Primera parte. Capítulo primero: Declaraciones, derechos y garantías; Capítulo segundo: Nuevos derechos y garantías (arts. 1 a 43).

(iii) Segunda parte. Autoridades de la Nación (arts. 44 a 129).

(iv) Disposiciones transitorias (desde la $1 .^{a}$ hasta la 17. ${ }^{a}$ ).

Esta división del universo de las normas constitucionales tendría bastante asidero, en especial, el literario. No podría mocionarse ni observarse que esta distinción, en cuatro partes, fue engendrada, propiamente, por el creador. Porque los redactores de la Constitución federal, con luces y agonías, sencillamente mencionaron con el apodo de "partes» a la $1^{\text {a }}$ y a la $2^{\text {a }}$, que se corresponden con los ámbitos descritos en el párrafo anterior con los números (ii) y (iii), respectivamente. Durante muchos años, señeramente antes de la reforma constitucional de 1994, solía apelarse a esta caracterización. Una reseña de la opinión prevalente de la dogmática arrojaría el citado como posible resultado. A partir de 1963-1964, Bidart Campos instaló la denominación de un Derecho constitucional de la libertad y de un Derecho constitucional del poder, como porciones o partes eminentes de la Constitución, desde su peculiar perspectiva trialista del mundo del Derecho, que incluía norma, valor y conducta. En la actualidad, con fines pedagógicos, suele sostenerse la división en dos partes. Otros comentarios distinguen tres partes: el preámbulo, el cuerpo y los apéndices ${ }^{47}$.

46 El hombre utiliza palabras para designar las cosas y sus estados, según se dan o se presentan en su mundo externo. El lenguaje escrito es una de las más maravillosas invenciones humanas. Estrictamente, la palabra «preámbulo» no se encuentra escrita en la Constitución federal. La reproducción facsimilar de la pieza original de mayo de 1853 puede compulsarse en la magnífica obra de Emilio Ravignani: Asambleas Constituyentes Argentinas (Instituto de investigaciones históricas de la Facultad de Filosofía y Letras, Universidad de Buenos Aires, Peuser, Buenos Aires, t. VI, $2^{\mathrm{a}}$ parte); precisamente, allí, en la p. 793 se encuentra el texto originario, sin inscripción previa, o sea: no dice «preámbulo» (también puede consultarse en Internet en el sitio de la CSJN: Biblioteca digital). En la misma publicación, p. 871, se reproduce el texto originario, según la redacción producida por la Convención Nacional «ad hoc», en septiembre de 1860: la historia se repite. En el portal del Senado de la Nación, la CFA comienza con la palabra «preámbulo». Naturalmente, todos en la Argentina denominan "preámbulo» a los enunciados que encabezan la norma fundamental.

47 Sagüés, Néstor P.: Manual de Derecho constitucional, Astrea, Buenos Aires, 2007, pp. 33 y 55. 
La CFA es un existente mundano, no tan asible o representable como la estructura de un violín, la extensión de un río, la anatomía de un pájaro o la forma de una planta, pero sí mucho más que la entidad significada por un unicornio. Conocer su forma de ordenación, dirección y unidad de la realidad política implica generar una relación cognoscitiva. Todo el conocimiento consiste en establecer vínculos o relaciones externas entre el sujeto cognoscente y el objeto. Al interesarnos por la descripción de sus piezas constituyentes, o partes o porciones normativas, debemos producir proposiciones o afirmaciones, cuyo grado de verdad nunca es absoluto.

Una comprensión analítica de la realidad siempre pone de manifiesto o enfatiza que lo complejo depende de la existencia de lo simple, no a la inversa. Mi tesis principal, en este aspecto, es que la CFA tiene cuatro partes, o mejor dicho: cuatro partes son los constituyentes de la totalidad, de la complejidad, que así se conceptúa. Admitir, entonces, que tiene partes significa asumir o derivar que la CFA es un objeto complejo, no simple, porque lo simple no tiene partes y es indivisible ${ }^{48}$.

Primera parte. Simples declaraciones. El preámbulo.

Segunda parte. Los derechos y deberes fundamentales, que fijan el itinerario de la programación.

Tercera parte. El poder, cuya organización y control racional nos hace ilusionar cada día de nuestras vidas con que, si cada individuo es asegurado mediante la fuerza de todos, todos serán asegurados mediante las fuerzas unidas de los individuos, a condición, desde luego, de que se considere que el reforzamiento de las fuerzas de los individuos se produce por la unión de las fuerzas de la pluralidad ${ }^{49}$.

Cuarta parte. El poder de reforma, que permite ilustrar las virtudes del cambio formalizado sobre el reposo divino.

Los marcos de referencia y los contenidos de cada una de estas cuatro partes son ilustrados, brevemente, en los próximos cuatro parágrafos. No se construyen proposiciones blindadas, apenas una descripción breve.

\footnotetext{
${ }^{48}$ V. Russell, Bertrand: Análisis filosófico, Paidós, Barcelona, 1999, p. 65.

49 Cfr. Feuerbach, Anselm von: Anti-Hobbes. $O$ sobre los limites del poder supremo y el derecho de coacción del ciudadano contra el soberano, Hammurabi, Buenos Aires, 2010, pp. 71/72.
} 


\section{IV.3. Simples declaraciones}

Son enunciados no normativos, que carecen de normatividad propia. La adquieren a partir de su integración en un sistema normativo. El preámbulo y las Disposiciones transitorias son un gran ejemplo. Veamos.

\section{IV.3.A. El preámbulo de una constitución}

El preámbulo de una constitución se compone con las letras que anteceden al cuerpo principal de la obra. Es un discurso del constituyente que trata de anticipar el contenido del Derecho constitucional. E identificar los valores fundamentales y su grado de objetivación jurídica en el pensamiento del constituyente; especialmente en los campos de la economía, la política, la cultura y, por supuesto, el Derecho ${ }^{50}$. Son puros enunciados de identidad que tienen entidad para describir las aspiraciones culturales de una ciudadanía abierta.

Una investigación preliminar y rudimentaria sobre el origen de estas fórmulas indica que el preámbulo fue una «creación norteamericana» ${ }^{51}$. Actualmente, todas las constituciones sudamericanas poseen un discurso anticipatorio realizado por el propio constituyente fundador, excepto la de Chile. El argentino es el más antiguo: data de 1853. El más joven es el boliviano: creado en 2009. La citada Constitución de Bolivia y también la de Ecuador 2008, por ejemplo, han procedido en sus preámbulos ${ }^{52}$ a reconocer los «derechos de la naturaleza» ${ }^{53}$.

Los preámbulos casi siempre contienen hipérboles. Una lectura crédula sobre estas exageraciones tiene que aceptarlas y poner el estado de cosas en su lugar.

La fuente del preámbulo de la CFA admite poca discusión. El cotejo que se sugiere en el cuadro permite individualizar, en este caso, al Derecho constitucional comparado que operó, como fuente indirecta, en la génesis del preámbulo argentino.

50 Literatura fundamental: V. Häberle, Peter: El Estado constitucional, UNAM, IIJ, México, 2003, p. 92.

51 V. Sánchez Viamonte, Carlos: Manual de Derecho constitucional, Kapelusz, Buenos Aires, 1959 , p. 72.

52 Se dispuso en el preámbulo de la Constitución de Ecuador: «Nosotras y Nosotros, el pueblo soberano del Ecuador (...) Celebrando a la naturaleza, la Pacha Mama, de la que somos parte y que es vital para nuestra existencia...». La Constitución de Bolivia enuncia en su preámbulo: «...Nosotros, mujeres y hombres, a través de la Asamblea Constituyente y con el poder originario del pueblo, manifestamos nuestro compromiso con la unidad e integridad del país. Cumpliendo el mandato de nuestros pueblos, con la fortaleza de nuestra Pachamama y gracias a Dios, refundamos Bolivia».

53 Literatura fundamental: Zaffaroni, E. Raúl: La Pachamama y el humano, Colihue, Buenos Aires, 2011. 


\begin{tabular}{l|l}
\hline $\begin{array}{c}\text { Constitución de EE.UU., sancionada } \\
\text { el } \mathbf{1 7} \text { de septiembre de 1787 }\end{array}$ & $\begin{array}{c}\text { Constitución de la Confederación } \\
\text { Argentina, sancionada el } \mathbf{1} \text { de mayo de 1853 }\end{array}$ \\
\hline $\begin{array}{l}\text { We the People of the United States, in Or- } \\
\text { der to form a more perfect Union, establish }\end{array}$ & $\begin{array}{l}\text { Nos los Representantes del Pueblo de la } \\
\text { Confederación Argentina, reunidos en Con- } \\
\text { greso General Constituyente por voluntad y }\end{array}$ \\
$\begin{array}{l}\text { Justice, insure domestic Tranquility, provi- } \\
\text { de for the common defence, promote the } \\
\text { general Welfare, and secure the Blessings of } \\
\text { Liberty to ourselves and our Posterity, do } \\
\text { ordain and establish this Constitution for } \\
\text { the United States of America. }\end{array}$ & $\begin{array}{l}\text { en cumplimiento de pactos preexistentes, } \\
\text { con el objeto de constituir la unión nacional, } \\
\text { afianzar la justicia, consolidar la paz interior, } \\
\text { proveer a la defensa común, promover el } \\
\text { bienestar general, y asegurar los beneficios de } \\
\text { la libertad para nosotros, para nuestra poste- } \\
\text { ridad, y para todos los hombres del mundo } \\
\text { que quieran habitar en el suelo argentino: } \\
\text { invocando la protección de Dios, fuente de } \\
\text { toda razón y justicia: ordenamos, decreta- } \\
\text { mos y establecemos esta Constitución para }\end{array}$ \\
la Confederación Argentina.
\end{tabular}

Resulta evidente que los textos comparten la enumeración de seis directivas: unión, justicia, paz, defensa común, bienestar general y libertad. En dos contextos de tiempo y lugar muy distintos. Además, nótese, que existen diferencias de grado en la conquista y desarrollo de la «unión», la «justicia», la «paz». La «defensa común», el «bienestar general»y los beneficios de la «libertad», en cambio, son muy similares, con una radical excepción: el mensaje de clara fuente alberdiana de puertas abiertas: «para todos los hombres del mundo que quieran habitar en el suelo argentino», enunciado que configura verdadera originalidad en el Derecho constitucional comparado. Por último: el preámbulo de la Constitución de Estados Unidos de 1787 no invoca a Dios, no menciona a las entidades preexistentes (las colonias) ni los actos anteriores a ella (la declaración de la independencia, 4 de julio de 1776), y fue ordenada y establecida por el «pueblo» de los Estados Unidos. En el argentino se deja constancia de que la legitimación del poder originario se fincó en los «representantes» del «pueblo» por «voluntad y elección de las «Provincias» que la componen.

Se discute la cotización normativa de los preámbulos. En Brasil, por ejemplo, la literatura y la jurisprudencia ${ }^{54}$ niegan vinculación o fuerza normativa al prólogo de la Constitución de 1988. En la Argentina no es una cuestión pacífi-

54 Así decidieron los miembros del Supremo Tribunal Federal, por unanimidad, el 15/8/2002, en la causa ADI-2076. 
$\mathrm{Ca}^{55}$. Históricamente, la CSJN negó que el preámbulo fuese útil para aumentar reglas sobre derechos o sobre la distribución del poder, sin desconocer que se trataba de un elemento de interpretación. No obstante, en 1974 se resolvió que el objetivo preeminente, según determina el preámbulo, es lograr el «bienestar general», la justicia en su más alta expresión, esto es, la justicia social, cuyo contenido actual consiste en ordenar la actividad entre los miembros de la comunidad y los recursos con que ésta cuenta con vistas a lograr que todos y cada uno de ellos participen de los bienes materiales y espirituales de la civilización ${ }^{56}$. Recientemente, el Más Alto Tribunal hizo suyas las palabras de Juan Bautista Alberdi ${ }^{57}$ :

El preámbulo [en que la Constitución] expresa sumariamente las grandes miras que presiden a sus disposiciones [enumera, entre otras varias, la de promover el bienestar general y asegurar los beneficios de la libertad para nosotros y para todos los hombres del mundo que quieran habitar el suelo argentino].

El preámbulo es un enunciado no normativo que integra el sistema normativo constitucional, por lo tanto: forma parte de él y por eso adquiere juridicidad. No tiene una normatividad directa; su realización es indirecta, porque a partir de sus enunciados se pueden realizar otras normas. Es un encabezamiento que sintetiza la programación que hace la CFA; en el peor de los casos, sirve como sustento de una argumentación o apoyo de un argumento sobre las propias normas constitucionales. Aunque se niegue esta afirmación, entiendo que no podría negarse esta otra fuertemente inspirada en la escrita por Eduardo Galeano $^{58}$ : el preámbulo está en el horizonte, me acerco dos pasos, él se aleja dos pasos. Camino diez pasos y él se desplaza diez pasos más allá. ¿Entonces, para qué sirve el preámbulo? Para eso: sirve para caminar, y para desarrollar nuestra

55 V. Ekmekdjian, Miguel A.: Tratado de Derecho constitucional. Constitución de la Nación Argentina, comentada, y anotada con legislación, jurisprudencia y doctrina, Depalma, Buenos Aires, 1993, t. I, pp. 75-78.

56 V. In re «Miguel A. Bercaitz», CSJN, Fallos, 289:430 (436), suscrito por Arturo E. Sampay, Cayetano Giardulli, Oscar de Roza Igarzábal y Felipe S. Pérez, pronunciado el 13/9/1974.

57 V. «Argenova S.A. v. Provincia de Santa Cruz», CSJN, Fallos, 333:2367, considerado 12, suscripto por Ricardo Lorenzetti, E. Raúl Zaffaroni, Juan C. Maqueda y Carlos Fayt, dictado el 14/12/2010. La cita de Alberdi, Juan Bautista: Sistema económico y rentístico de la Confederación Argentina, según su Constitución de 1853, en sus Obras completas, t. IV, La Tribuna Nacional, Buenos Aires, 1886, p. 153.

58 Escribió Eduardo Galeano: «La utopía está en el horizonte. Camino dos pasos, ella se aleja dos pasos y el horizonte se corre diez pasos más allá. ¿Entonces para qué sirve la utopía? Para eso, sirve para caminar» (v. Las palabras andantes, Siglo XXI Editores, Buenos Aires, 2010, p. 310). 
identidad individual en la comunidad (si lo deseamos) y la propia identidad de la comunidad en cada uno de nosotros (siempre que estemos de acuerdo).

\section{IV.3.B. Disposiciones transitorias}

La CFA nunca contuvo Disposiciones transitorias ${ }^{59}$. No se empleó la técnica en la redacción originaria: 1853-1860. Los cambios de 1866, 1898 y 1957 no diseñaron enunciados transitorios. La reforma constitucional de 1994 fue profunda, pero no cambió el escenario normativo. Pese a la gran cantidad de cuestiones que el poder constituyente no pudo resolver por escasez de tiempo o falta de acuerdo, simplemente, se dio el puntapié inicial con la convicción de que la reglamentación la haría el Congreso federal en el futuro. Una segunda característica fue la cantidad de Disposiciones transitorias: diecisiete en total; una de ellas, precisamente la Primera, condensa un reclamo:

La Nación Argentina ratifica su legítima e imprescriptible soberanía sobre las Islas Malvinas, Georgias del Sur y Sandwich del Sur y los espacios marítimos e insulares correspondientes, por ser parte integrante del territorio nacional. La recuperación de dichos territorios y el ejercicio pleno de la soberanía, respetando el modo de vida de sus habitantes, y conforme a los principios del derecho internacional, constituyen un objetivo permanente e irrenunciable del pueblo argentino.

La reclamación tiene sólidos argumentos jurídicos. Se trata de una forma de colonialismo tardío ${ }^{60}$; dominación que jamás poseyó justificación racional, menos todavía en pleno siglo Xxi. Nótese que, equivocadamente, el redactor del enunciado refirió como sujeto a la «Nación» cuando, en realidad, la soberanía corresponde al Estado. Aunque la voluptuosidad de los sentidos debe hallarse gobernada por la razón ${ }^{61}$, no hace falta predicar que la soberanía sobre las Islas

59 Toda afirmación rotunda corre riesgos en el mundo del Derecho. En la CFA, según su texto de 1853 se dispuso: «La Constitución puede reformarse en el todo o en cualquiera de sus partes, pasados diez años desde el día en que la juren los Pueblos». Si quiere ser calificada como transitoria, queda abierto el comentario... Pese a ello, no desdice la regla general.

${ }^{60}$ E. Raúl Zaffaroni distingue tres etapas del colonialismo en nuestra región: a) la del colonialismo en sentido estricto practicado por las potencias ibéricas hasta el siglo XIX; b) la del neocolonialismo, ejercido por la nueva hegemonía mundial a la caída de los decadentes imperios ibéricos, en especial Gran Bretaña; y c) la actual, de tardocolonialismo o etapa superior del colonialismo. V. «Descolonización y poder punitivo», Contextos, nº 3, Defensoría del Pueblo de la Ciudad de Buenos Aires, 2012, pp. 41-58.

${ }^{61}$ Leibniz, Gottfried: «La sabiduría», en Tres ensayos: El Derecho y la equidad. La Justicia y la Sabiduría, UNAM, 1960, cuaderno 7, p. 298. 
Malvinas y otras encierre, probablemente, uno de los sentimientos constitucionales más homogéneos de la ciudadanía argentina.

\section{IV.4 Los derechos y deberes fundamentales}

IV.4.A. Los derechos fundamentales

La CFA es liberal, en el sentido de que su finalidad originaria es la garantía de la libertad, aunque pueda ponerse en duda si en el momento original, todos los ciudadanos fueron igualmente libres para contratar o para decidir no hacerlo. Existió, creo, en 1852-1953 y 1860 una persistente desigualdad en los beneficios de la libertad, que quizá se haya corregido, parcialmente, durante el siglo XX con el aumento de la noción de ciudadanía.

Pero volvamos a nuestro tema. Para concretar la idea de libertad, en la Ley Mayor de la Argentina se plantean dos piezas elementales: la regla de la autodeterminación y soberanía individual, que importa un ámbito de libertad de la persona ilimitada como pauta regia, mientras que la facultad del Estado para invadirla es limitada; y la regla que da arquitectura y organiza, vertical y horizontalmente, el poder del Estado, al dividirlo y encerrarlo en un sistema de competencias tan detalladas como determinadas y circunscriptas.

La determinación o la creencia en la libertad y la organización de la autoridad es la díada que el constituyente sistematizó en 1853-1960.

La libertad es el gen de todos los derechos fundamentales, porque todos los derechos derivan de la libertad o la libertad es su fuente de nutrición. Libertad entendida como libertad negativa: soy eminentemente libre en la medida y circunstancia que ningún hombre ni ningún grupo de hombres interfieren en mi actividad. Libertad entendida como libertad positiva: el deseo del individuo de ser su propio amo, la firme posibilidad de orientar la voluntad hacia un objetivo, adoptar decisiones, no ser accionado ${ }^{62}$.

Libertad negativa y libertad positiva se corresponden con la idea de que nadie puede privar a nadie de la libertad y nadie debe disfrutarla a expensas de otro o de otros. La igualdad en la libertad es la libertad jurídica que capta la CFA en su artículo 19. La CFA no es una constitución igualitaria. No rechazo el igualitarismo, pero tampoco construiré un terreno para la constitución, que no coincide con su normatividad específica.

${ }^{62}$ Berlin, Isaiah: «Dos conceptos de libertad», en la obra Sobre la libertad, Alianza, Madrid, 2009, pp. 205-255. 
Derechos fundamentales y derechos humanos suelen comprenderse, en general, con idéntico campo semántico. No obstante, si la identidad también implica aceptar que son temporalmente eternos y espacialmente tienen validez en todo el mundo, se prefiere el empleo de «derechos fundamentales», en la inteligencia de que son creados por el hombre y garantizados por instituciones concretas, y son subjetiva y objetivamente válidos. La misma distinción y conclusión vale para derechos subjetivos, porque no hace falta decir que los derechos fundamentales implican potestades o inmunidades individuales, plurales o colectivas.

Los derechos fundamentales, en sentido jurídico, son «derechos» porque son conferidos a los hombres por normas, es decir, por el sistema jurídico inaugurado por la CFA. Los derechos fundamentales, en sentido jurídico, se distinguen de los derechos morales porque los primeros son relativos o pertenecientes al sistema jurídico positivo estatal que los confiere. Los derechos morales también pertenecen a un sistema normativo: el moral.

Los derechos fundamentales son fundamentales no porque constituyan el cimiento del edificio de la CFA, ni tampoco el origen de la CFA, porque una constitución puede existir sin mencionar o describir derechos fundamentales. No se trataría de una circunstancia elogiosa, pero es teóricamente pensable. Son fundamentales porque por su intermedio se realiza y afianza la libertad. Precisamente son fundamentales porque significan una línea de acción para el desarrollo de la fuerza del Estado. Implican, por ende, en su fundamentalidad, una condición primera o marco de referencia inexcusable, que de otra forma vaciaría a la libertad. Fundamento, pues, es sinónimo de razón de ese hombre artificial que se denomina estado. Pienso que razón determinante o suficiente es una correcta delimitación conceptual. También se los puede denominar razones de peso ${ }^{63}$.

En el régimen organizado en la actualidad por el sistema constitucional federal hay derechos expresamente enumerados o reconocidos — por ejemplo, los enunciados en los arts. 14, 14 bis, 16, 17, 18, 19, 20, 36, 37, 38, 39, 40, 41, 42 y 43 de la CFA - y hay también derechos implícitos que nacen de la soberanía del pueblo y de la forma republicana de gobierno, según la disposición que formula el artículo 33 de la Constitución federal al respecto. La reforma constitucional ha ampliado el elenco de los derechos enumerados en el texto constitucional por vía de la jerarquización del Derecho internacional de los derechos humanos (arg. art. 75, inc. 22), haciendo que, hoy por hoy, el sistema jurídico constitucional federal de la Argentina disponga de reglas que reconocen expresamente las tres generaciones de derechos: los derechos de primera generación (civiles y

${ }^{63}$ V. Leibniz, Gottfried: Escritos filosóficos, Editorial Charcas, Buenos Aires, 1982, p. 370. 
políticos), los derechos de segunda generación (sociales, culturales y económicos) y los derechos de tercera generación, que incluyen el derecho a la paz, a la cultu$\mathrm{ra}$, a un medioambiente sano y a la juridicidad constitucional. No obstante, tal generalización no es extensible a las garantías respectivas, las que, comparadas con la declamación de derechos subjetivos, han quedado a mitad de camino.

En el orden instaurado por el sistema jurídico constitucional argentino, las personas, y excepcionalmente grupos de personas, o sea quienes integran la población del Estado, son quienes titularizan activamente los derechos fundamentales, de fuente o jerarquía constitucional.

\section{IV.4.B. Los deberes u obligaciones}

Plantear la existencia de derechos fundamentales significa definir, al mismo tiempo, la existencia de deberes u obligaciones que nacen por el establecimiento de una constitución.

Las obligaciones o deberes se encuentran tanto a cargo del Estado como de los ciudadanos y/o habitantes. No se penetra aquí en la clasificación, en sí misma, ni en la descripción detallada de los deberes fundamentales. Sin embargo, son susceptibles de ser clasificados en función del sujeto, del objeto, de la naturaleza o del enunciado ${ }^{64}$.

La primera y principal obligación constitucional consiste en su simple y liso acatamiento. Por todos: ciudadanos y servidores se encuentran obligados por el Derecho constitucional que emana de la constitución. En el caso de la Argentina, a nivel federal, así surge del juego de los artículos 31 (ley fundamental del Estado) y 19 (debe respetarse el orden jurídico: ningún habitante se encuentra obligado a hacer lo que no manda la ley ni privado de lo que ella no prohíbe; ergo — cae de maduro - correctamente puede inferirse la imperatividad para lo ordenado!). El rasgo dominante de la CFA es su normatividad; su obligatorio y leal acatamiento, por la autoridad gubernativa y los ciudadanos, resulta inherente a su propia concepción. No tendría sentido una constitución que no fuese normativa, desde que la constitución organiza la convivencia comunitaria. Por eso, la autoridad de la CFA, su acatamiento, es porque se yergue sobre ciudadanos y servidores públicos. La autoridad de la CFA, como se afirma, implica la extensa y acabada obligación de cumplirla. Además, el nuevo artículo 36 constitucional —introducido en 1994 - refuerza la narración porque, al fijarse como regla de oro que la CFA «mantendrá su imperio aun cuando se interrumpiere su observancia por actos de fuerza contra el orden institucional y el sistema demo-

${ }^{64}$ Sagüés, Néstor: Manual de Derecho constitucional, Astrea, Buenos Aires, 2007, p. 929. 
crático», sin claudicar y con transparencia, se consagra positivamente la propia autoridad de la Constitución federal en el propio texto.

Se observan deberes fundamentales del ciudadano y/o habitante. Una contemplación abierta, en este caso del artículo 5 de la CFA (obligación de los entes autónomos de dictar una constitución, que, entre otros estados de cosas, asegure la educación primaria), descubriría, además, que existe una segunda obligación básica: acceder a la educación primaria.

Constituye también un tercer deber constitucional el sufragar. Elegir un candidato o no elegir un candidato para cargo público electivo. La CFA no es indolente: obliga a participar al ciudadano y de allí se deriva que quedará sometido al orden jurídico que él mismo por derecho propio y en nimia medida construye con su propio poder electoral, según dispone el artículo 37 constitucional.

Un cuarto deber es casi natural: hay que contribuir al sostenimiento y desarrollo de un Estado; se trata de obligación de primer orden, porque sin tributos no hay Estado. El deber de tributar, entre otras normas, se encuentra previsto en los artículos 4, 16 y 75, inciso 2 de la CFA. Ciertamente: el artículo 16 constitucional declara que la igualdad es la base del impuesto, aunque en ningún fragmento de la CFA existan referencias a la progresividad o a la regresividad, claves de la política tributaria.

El artículo 21 establece la obligación de armarse en defensa de la propia CFA.

Los deberes fundamentales, en el marco propuesto, al igual que los derechos fundamentales, no son absolutos, porque así lo dispone el artículo 28 constitucional. En paralelo, el reconocimiento de los derechos fundamentales configura deberes correlativos en cada persona y en el propio Estado: respetar el derecho fundamental de otro u otros sujetos.

En resumen: no hay contradicción entre derechos y deberes fundamentales. Los deberes que se individúan para el ciudadano son básicamente de educación, de tributación, de armarse en defensa de la juridicidad estatal y de votar.

Llegan «obligaciones fundamentales», que tienen jerarquía constitucional desde: a) la Declaración Americana de los Derechos y Deberes del Hombre, artículos 29 a 38; b) la Convención Americana sobre Derechos Humanos, artículo 32, y c) la Declaración Universal de Derechos Humanos, artículos 1 y 29.

El Estado, por su parte, tiene infinidad de obligaciones: la primera es que los integrantes de los poderes cumplan su tarea racionalmente, según mandan los artículos 1 y 28 constitucionales. La racionalidad, por cierto, se empalma con la ausencia de contradicción interna y externa en cada uno de sus actos. Además, todo el Derecho Internacional de los Derechos Humanos, en las condiciones de su vigencia y con jerarquía constitucional, dispone múltiples formas y 
mecanismos de deberes y obligaciones por parte de los Estados. Al respecto, se elige como síntesis de esta formulación el enunciado normativo de la Convención Americana sobre Derechos Humanos:

Artículo 1. Obligación de respetar los derechos.

1. Los Estados Partes en esta Convención se comprometen a respetar los derechos y libertades reconocidos en ella y a garantizar su libre y pleno ejercicio a toda persona que esté sujeta a su jurisdicción, sin discriminación alguna por motivos de raza, color, sexo, idioma, religión, opiniones políticas o de cualquier otra índole, origen nacional o social, posición económica, nacimiento o cualquier otra condición social.

2. Para los efectos de esta Convención, persona es todo ser humano.

Artículo 2. Deber de adoptar disposiciones de derecho interno.

Si el ejercicio de los derechos y libertades mencionados en el artículo 1 no estuviere ya garantizado por disposiciones legislativas o de otro carácter, los Estados Partes se comprometen a adoptar, con arreglo a sus procedimientos constitucionales y a las disposiciones de esta Convención, las medidas legislativas o de otro carácter que fueren necesarias para hacer efectivos tales derechos y libertades.

\section{IV.5. El poder y su control}

Por amor a la claridad se advierte que el término «poder» condensa varios significados. En un sentido, se refiere a la clase de actos de quienes ejercen funciones estatales con competencia delimitada; así, el presidente tiene poder al administrar la república; los legisladores, al crear normas de alcance general, y los jueces, al resolver conflictos, porque su principal atención consiste en sostener el sistema jurídico en su unidad y coherencia. En una segunda orientación, «poder» se refiere al órgano del Estado que ejerce la potestad o competencia, los poderes constituidos: poder legislativo, poder ejecutivo y poder judicial. Para evitar confusiones, de ahora en adelante, en principio, la expresión es usada en el segundo sentido, aludiendo a la función que denota una actividad: aquella que dispone de la fuerza indispensable para realizar los actos cotidianos, ordinarios, que exige la gobernabilidad del Estado. No es un poder «desnudo», es decir, como aquel fundado en la tradición y el simple asentimiento. Se trata de un 
poder que puede ser definido «como la producción de efectos deseados» ${ }^{65}$ sobre los hombres.

La división de los poderes estatales tiene por inocultable finalidad contribuir a la consecución de lo que cotidianamente parece imposible, o digno de una de las más fantásticas de las utopías: someter el poder al cumplimiento de reglas de juego jurídicas preestablecidas. Se trata de impedir la concentración de los poderes. El fraccionamiento del poder del Estado era - y es - un formidable escudo de protección para la libertad de los habitantes.

La distribución del poder genera la aparición de departamentos gubernativos distintos, a quienes se encarga la formación de la voluntad estatal. La técnica utilizada por los redactores de la Constitución federal de la Argentina — se insiste- - en el plano estrictamente normativo, era uno de los antídotos más eficaces que se conocían a mediados del siglo XIX para evitar la concentración del poder y asegurar cierto espacio para la libertad de las personas. La Corte Suprema de Justicia de la Nación, desde el siglo XIX, invariablemente ha sostenido que es una regla elemental de nuestro Derecho público que cada uno de los tres altos poderes (legislativo, ejecutivo y judicial) que forman el gobierno de la Nación aplica e interpreta la Constitución federal por sí mismo, cuando ejercita las facultades que ella le confiere y asienta ${ }^{66}$.

La orientación jurídica del Estado es la federal. Significa la partición vertical del poder: los entes autónomos (veintitrés provincias y la Ciudad de Buenos Aires) y el Estado federal. Los entes autónomos conservan todo el poder no delegado por la CFA al Estado; básicamente, el federalismo es organizado a partir del detalle normativo anclado, de modo expreso o implícito, en los contenidos de los siguientes artículos constitucionales: 1 a 13, 23, 25, 26, 27, 29, 31, 32, 33, 34, 44, 45, 54, 75 y 121 a 129. No existe la posibilidad de secesión. La igualdad es la regla para la configuración de la forma federal.

La forma de gobierno adoptada es la republicana. Significa la partición horizontal del poder: asignación de potestades o competencias estrictamente delimitadas en tres departamentos; además de un Ministerio Público encargado de promover la defensa de la legalidad de los intereses generales de la sociedad, en coordinación con las demás autoridades de la república.

Condición elemental para el ejercicio de la función republicana es la idoneidad.

${ }^{65}$ V. Russell, Bertrand: «Las formas del poder», en El poder en los hombres y en los pueblos, Losada, Buenos Aires, 1960, pp.37-36.

66 «Joaquín M. Cullen v. Baldomero Llerena», CSJN, Fallos, 53:420, resuelto el 7/9/1883, suscrito por Benjamín Paz, Ariel Bazán, Octavio Bunge y Juan Torrent. 
La atribución de competencias comporta la existencia de zonas de reserva, o mejor dicho: potestades específicamente descritas, que no deben ni pueden ser invadidas por otro órgano, so pena de sanción. Ciertamente: existen ámbitos de competencias concurrentes, por ejemplo la formación de la ley, que es un acto entre el órgano Congreso y el órgano ejecutivo, pero, aun en dicho caso, cada órgano tiene una competencia propiamente asignada e indelegable.

La república es objeto de definición o descripción o referencia implícita, entre otros, en los artículos constitucionales 1, 5, 6, 13, 15, 16, 18, 19, 22, 28, $36,37,38,44$ a 84, 87 a 120. La elección, antecedida por la deliberación, es la regla para la configuración de la república.

\section{IV.6. La reforma}

La función propia del poder constituyente es la de configurar e instaurar la Constitución. De ella brota el Derecho constitucional.

El poder de cambiar la constitución, generalmente sometido a reglas de competencia prefijadas, es un poder político porque provoca variaciones en la Constitución federal.

La reforma de la Constitución, por expansión o contracción o revisión de las normas, genera una nueva combinación de enunciados normativos y no normativos, cuya combinación constituye precisamente el objeto Derecho constitucional.

Sobre la dimensión de la reforma, es la propia Constitución federal la que contiene dos enunciados básicos. Recuérdese, en primer lugar, como ilustra el preámbulo, que fueron los representantes del pueblo argentino los que la ordenaron, la decretaron y la establecieron. El valor de verdad de esta proposición, que desempeña un papel clave en el sistema constitucional argentino, jamás fue desmentido pero sí quebrantado. Por eso, de acuerdo con esta caracterización, sin mayores esfuerzos puede decirse que, si la constitución política estatal es la decisión del pueblo, la reforma también debe serlo. Ergo, el plan constitucional debe ser decidido por su creador: el cuerpo electoral.

Ordenar, decretar y establecer una constitución — como dice el preámbulo de la CFA - no prohíbe que «otra» ley fundamental pueda, en el futuro, también ser establecida. Si sólo el poder del pueblo crea el sistema constitucional que organiza al Estado, cabe especular que, cuando se aparta de tal función instrumental, el Derecho constitucional deja de ser la razón que reglamenta la fuerza, pasando a ser el poder coactivo mismo. La Constitución federal es un esfuerzo por contener al poder; cuando desaparece la distinción, se desvanece la idea de que el poder público es ejercido por el pueblo por intermedio del sufragio. 
En segundo lugar, es el poder de reforma constitucional y su propio contenido el que puede generar un nuevo punto de llegada. Se trata de una cuestión intrínsecamente política: la creación de la norma mayor. Esta puerta es abierta por el artículo 30 de la Ley Mayor:

La Constitución puede reformarse en el todo o en cualquiera de sus partes. La necesidad de reforma debe ser declarada por el Congreso con el voto de dos terceras partes, al menos, de sus miembros; pero no se efectuará sino por una Convención convocada al efecto.

Tal como se encuentra diseñado por el artículo 30 constitucional, y en conexión con el artículo 23 de la Convención Americana de Derechos humanos, el proceso constituyente consta de tres etapas: a) iniciación; b) deliberación pública y elección ${ }^{67}$, y c) producción constituyente: creación constitucional.

Una reforma constitucional es la que produce un cambio en el contenido del sistema, pero no produce la destrucción del preexistente, al mantener la continuidad.

La Constitución federal no es eterna sino tan sólo permanente. Porque ninguna ley existe de esa entidad o naturaleza. La Constitución federal no alienta el reposo. Tampoco detiene el cambio político. Específicamente instituye una suerte de conversación entre generaciones que no se han conocido y probablemente no se conocerán. Pienso que ésta, y no otra, es la forma más persuasiva y la que mejor sirve para explicar la forma de obligar de la Ley Mayor y sus posibilidades de cambio.

${ }^{67}$ A partir de la reforma de 1994, el art. 23 de la CADH goza de jerarquía constitucional. En la obra Reforma constitucional y control de constitucionalidad, Porrúa, México D.F., 2007, concretamente en las pp. 404-410, justifico las razones por las que se considera obligatorio presentar al cuerpo electoral, con carácter previo, la naturaleza y contenido de los temas constitucionales que pretenderían ser objeto de cambio. Se dispone específicamente en el citado artículo: «Derechos Políticos. 1. Todos los ciudadanos deben gozar de los siguientes derechos y oportunidades: a) de participar en la dirección de los asuntos públicos, directamente o por medio de representantes libremente elegidos; b) de votar y ser elegidos en elecciones periódicas auténticas, realizadas por sufragio universal e igual y por voto secreto que garantice la libre expresión de la voluntad de los electores, y c) de tener acceso, en condiciones generales de igualdad, a las funciones públicas de su país. 2. La ley puede reglamentar el ejercicio de los derechos y oportunidades a que se refiere el inciso anterior, exclusivamente por razones de edad, nacionalidad, residencia, idioma, instrucción, capacidad civil o mental, o condena, por juez competente, en proceso penal». 


\section{MECANISMOS GARANTISTAS}

\section{V.1. Diseño}

En línea con lo expresado en la sección III, se postula que la constitución es ley mayor del sistema jurídico, a condición de que su vulneración no quede como mera práctica antinormativa. La fuerza normativa de la constitución depende centralmente de la planificación de sus propias garantías.

Se contempla a las garantías, en sentido amplio, como el mecanismo ${ }^{68}$ con mayor aptitud para procesar las pretensiones de vigencia de las normas de la constitución. Constituyen un mecanismo del sistema constitucional porque se integra, precisamente, con los procesos internos que la hacen funcionar. No obstante, las formas y cualidades de cada una de ellas es tan disímil como la constitución misma y, por ende, diversa como es la diversidad de sistemas constitucionales existentes en los Estados que las regulan.

La constitución escrita del Estado es un modelo que, naturalmente, como es dable esperar de toda obra humana, experimentará en su desarrollo intentos de modificación, quebrantamiento o transgresiones. Se asevera: la constitución del Estado democrático vale o valdrá lo que valen o valdrían sus garantías. Ni más, ni menos.

Las garantías constitucionales son un mecanismo cabal, es decir: procesos previstos por el propio sistema para perseguir la instrumentación de su autodefensa, la concreta posibilidad de su realización integral.

Defender, tutelar, guardar, en fin, mantener indemne a la constitución consiste en protegerla contra las transgresiones o tentativas de quebrantamiento, por actos u omisiones que, paradoja o no, especialmente pueden provenir de las autoridades a cargo de los poderes constituidos del Estado designadas para hacer cumplir sus normas. Cuando se produce una violación del orden estipulado por el sistema de la constitución, por regla general, serán las garantías constitucionales las herramientas específicas que pueden ser empleadas para intentar restaurar y desarrollar su fuerza normativa.

El bloque garantista, directamente encastrado en la constitución, debe tener, pues, por lo menos dos finalidades bien definidas: la primera, proteger y satisfacer los derechos fundamentales; y la segunda, asegurar las formas jurídicas y políticas del Estado y su sistema de gobierno. De dicha concepción se deriva la posibilidad de formulación del siguiente elenco de garantías constitucionales: a) garantías de

68 Enseña el maestro Mario Bunge que un mecanismo es «cualquier proceso que hace que un objeto complejo funcione». V. Emergencia y convergencia. Novedad cualitativa y unidad del conocimiento, Gedisa, Barcelona, 2004, pp. 45-60. 
la constitución; b) garantías de los derechos fundamentales; c) garantía orgánica del Defensor del Pueblo; y d) garantía de acceso a la jurisdicción supranacional.

Se colige entonces que:

Primero. Las garantías constitucionales son garantías de la constitución cuando son previstas para defender el sistema jurídico que ella organiza. La constitución se las confiere a sí misma para asegurar su jerarquía y primacía dentro del sistema jurídico estatal. Así, la constitución genera su propia garantía de inmanencia.

Segundo. También, cabe hablar con propiedad de garantías constitucionales, cuando se alude a los mecanismos específicamente diseñados para garantir o respaldar la vigencia de los derechos fundamentales, es decir, cuando son estipuladas para la reparación o satisfacción de los derechos individuales, grupales o colectivos a los que el texto normativo constitucional confiere reconocimiento.

Tercero: la garantía del Defensor del Pueblo, que es orgánica.

Cuarto: cabe agregar la garantía de acceso a la jurisdicción supraestatal para la defensa de los derechos fundamentales.

Seguidamente, se puede leer una descripción mínima y una posición de cada una de las cuatro garantías y las subespecies que contienen.

\section{V.2.A. Garantías de la constitución}

Por lo menos desde fines del siglo XVIII en adelante, se ha aspirado en muchos Estados a que el mundo político quedara sometido al Derecho. La herramienta paradigmática para llevar a cabo tal operación ha sido la constitución.

Si se está de acuerdo en que la constitución es una herramienta convencional de la cual se sirve el hombre racionalmente para facilitar la coexistencia y convivencia en paz, la actividad de las autoridades no puede ser otra que respetar y dar vida a cada una de las prescripciones del contrato político original. Bajo garantías de la constitución, en significación amplísima, se puede encerrar la idea que postula que las decisiones políticas se elaboren y ejecuten en virtud del marco que estatuye la constitución, y no contrariamente. Cuando se alude a este costado de su significación, se piensa en verdaderas garantías políticas que se da la propia constitución.

El examen del sistema constitucional federal de la Argentina permite la siguiente ilustración de los mecanismos que componen el subsistema denominado garantías de la constitución: 
(i) División horizontal (republicanismo) y vertical (federalismo y municipalismo) de las tareas de los poderes ${ }^{69}$;

(ii) Proceso de reforma constitucional;

(iii) Emergencias y autodefensa constitucional ${ }^{70}$;

(iv) Desarrollo progresivo de los derechos fundamentales por intermedio de la reglamentación a cargo del Congreso ${ }^{71}$;

(v) Estándar de racionalidad, mínimo aceptable, y función republicana ${ }^{72}$;

(vi) Control del Congreso ${ }^{73}$.

El repertorio de garantías de la constitución muestra que se trata de limitaciones al margen de actuación de los poderes constituidos. Se trata, pues, de garantías cuyos destinatarios no son, directa y específicamente, las personas o grupos de personas, aunque por supuesto pueden invocarlas.

V.2.A bis. Entreacto. Interpretación y control judicial de la constitucionalidad

Una constitución jurisdiccionalmente garantizada es, presumiblemente, el paradigma de las garantías de la constitución.

${ }^{69}$ La separación, la distribución y el equilibrio de las funciones de los poderes del Estado, con la finalidad exclusiva de limitar el poder, es una clave de la CF.

${ }^{70}$ El plan de emergencias básico del Derecho Constitucional del poder: a) declaración del estado de sitio, $c f r$. arg. arts. 23 y 75 , inc. 29, de la CF; b) intervención federal a las provincias y la Ciudad de Buenos Aires, cfr. arg. arts. 5 y 75, inc. 31 de la CF; c) también cabe incluir en esta dimensión garantista del derecho de la constitución a las fórmulas normativas que reglan «la imperatividad y efectividad del orden constitucional frente a todo acto de fuerza que intente interrumpir su vigencia», como así también la consagración expresa del derecho de resistencia de la ciudadanía contra quienes atentaren en su contra (v. en este sentido, por ejemplo, art. 36 de la CF).

${ }^{71}$ Comportan igualmente una garantía de la constitución, bajo la óptica desde la cual se viene describiendo en este apartado, las reglas constitucionales que aseguran que la zona periférica de los derechos fundamentales será reglamentada, si fuere necesario, exclusivamente por ley emanada del órgano legislativo. Así, por ejemplo, las atribuciones legislativas que la Constitución federal de la Argentina confiere al Congreso en los arts. 75, 28 y concordantes de su propio texto. Por su parte, en el artículo 26 de la CADH se encuentra anclado el compromiso estatal para el desarrollo progresivo de los derechos económicos, sociales y culturales.

${ }^{72}$ Los principios que estipulan y precisan un ejercicio racionalmente justificable de los poderes del Estado, exigiendo un mínimo estándar de razonabilidad en los actos u omisiones de funcionarios a cargo de las distintas ramas del gobierno republicano (arts. 1, 28 y 33 de la CF).

${ }^{73}$ La distinta gama de controles políticos del Congreso se encuentra prescripta en la Constitución Federal de la República Argentina en los arts. 53, 59 y 60; 99, inc. 3, y 11; 75, inc. 8, $22,25,26,21 ; 29 ; 31 ; 32 ; 71 ; 104 ; 101 ; 83 ; 76$ y 100, inc. 12 . A cargo exclusivo del Senado: art. 99 , inc. 4,7 y 19 . 
La garantía jurisdiccional de la constitución, o control o revisión de constitucionalidad de la normativa y actividad infraconstitucional, es el mecanismo para garantizar que la constitución se mantenga como la norma mayor del sistema. Además, la garantía jurisdiccional posibilita al Estado que, por su intermedio, pueda asegurar la estructura jerárquica de su sistema jurídico.

La garantía jurisdiccional de la constitución merece ser encuadrada tanto en el plano de las garantías de la constitución como en el de las garantías constitucionales para la defensa de los derechos constitucionales en particular, porque siempre tiene que ser estimulada por una parte dentro de un proceso, y la decisión se encuentra a cargo de un juez o tribunal.

El sistema federal argentino de control de constitucionalidad — capítulo medular de la interpretación judicial— surge de la realización de lo prescripto por los artículos $1,18,19,21,31,33,43$ y 116 de la CF.

\section{V.2.B. Garantías de los derechos fundamentales}

Las garantías de los derechos fundamentales son el mecanismo por excelencia para dotar de efectividad a los derechos y/o al normal desenvolvimiento de la vida constitucional. Su naturaleza es reactiva o defensiva porque operan en caso de vulneración o amenaza de lesión de un derecho fundamental o del estatuto de los poderes. Acudir a ellos significa intentar obtener, por su intermedio, la preservación del derecho o el reestablecimiento del equilibrio de los poderes.

Se enumeran, sin taxatividad:

(i) La garantía de acceso a la jurisdicción: el debido proceso legal (arts. 17 y 18 de la CF), en protección de la vida, la libertad, la igualdad, el ambiente, la propiedad y otros.

(ii) Acción constitucional de amparo (arts. 43 de la CF y 25 de la CADH);

(iii) Acción constitucional de hábeas data (art. 43 de la CF).

(iv) Acción constitucional de hábeas corpus (art. 43 de la CF).

(v) Acción popular en defensa de la juridicidad constitucional (art. 33 de la CF).

(vi) Institucionalización del amicus curiae (art. 33 de la CF).

(vii) Inviolabilidad del domicilio, de la correspondencia y de los papeles privados.

(viii) Jueces naturales. Prohibición de comisiones especiales. Prohibición de la confesión coercitiva (art. 18 de la CF).

(ix) Excepciones de inconstitucionalidad: planteo que puede realizarse en cualquier tipo de proceso, indicándose la colisión de una disposición con la Constitución o la interpretación de una regla de ésta; en hipótesis muy redu- 
cidas opera por vía directa, a tono con lo previsto por el artículo 322 de la ley procesal civil y comercial.

(x) recursos (extraordinario federal); es decir, el artículo 14 de la ley 48; basado en el artículo 31 de la CF

(xi) Garantías específicas dentro del proceso penal ${ }^{74}$.

\section{V.2.C. La garantía orgánica para la defensa de los derechos fundamentales}

La reforma constitucional de 1994 confirió estatus constitucional al Defensor del Pueblo, en el artículo 86 de la CF. El propio poder constituyente adoptó la decisión de prever la defensa institucional de los derechos fundamentales que la Constitución federal de la Argentina organiza y confiere, en los términos fijados en la norma.

\section{V.2.D. Garantía supraestatal para la defensa de los derechos fundamentales} estatuidos por el derecho de la constitución

En el artículo 44 de la Convención Americana sobre Derechos Humanos - $\mathrm{CADH}$ - se estipula que cualquier persona o grupo de personas, o entidad no gubernamental legalmente reconocida en uno o más Estados Miembros de la Organización, puede presentar a la $\mathrm{CIDH}$ peticiones que contengan denuncias o quejas de violación de las reglas jurídicas de la Convención por un Estado Parte ${ }^{75}$.

74 Entre ellas pueden descubrirse. a) Principios de legalidad y máxima taxatividad en materia penal. Irretroactividad de la ley penal. Retroactividad de la ley penal más benigna. Información del hecho imputado; b) Presunción de inocencia; c) Condiciones para la validez de la confesión del imputado. Inmunidad de la declaración del imputado; d) Libertad provisional: excarcelación y eximición de prisión; e) Defensa técnica: comunicación entre el inculpado y su defensor; f) Detención de personas, principio general: arresto sólo por orden judicial escrita; g) Publicidad del proceso penal; h) Peculiaridades del derecho de defensa y debido proceso: garantía de la doble instancia para recurrir el fallo ante juez o Tribunal Superior. Garantía a la asistencia letrada en proceso penal; i) Indemnización por indebida privación de libertad; j) Non bis in idem o garantía contra el doble juzgamiento; k) Derecho del imputado a obtener un pronunciamiento que ponga término del modo más rápido posible a la situación de incertidumbre y de innegable restricción de libertad que puede comportar el enjuiciamiento penal; 1) Garantías constitucionales para la ejecución de la pena: cárceles sanas y limpias; prohibición de la pena de muerte; prohibición de tormentos, azotes y penas o tratos crueles, inhumanos o degradantes ( $c f r$. arg. arts. 1, 18, 19, 28 y 33 de la CF y 7, 8, 9 y 10 de la CADH y 9, 10, 11, 14 y 15 del PIDCyP).

75 Agotados los procedimientos previstos en los arts. 48 a 50 de la Convención, y de no llegarse a una solución amistosa y demás recaudos procedimentales allí previstos, sólo la Comisión tiene derecho a someter el caso a la decisión de la Corte Interamericana de Derechos Humanos. Del juego de los arts. 63 y 67 de la Convención, surge que en el fallo que deba emitir la CIDH, 
La lectura del texto de la CADH no deja dudas: sus reglas son una garantía para la defensa de los derechos constitucionales al permitir la apertura y desenvolvimiento de la jurisdicción, también de naturaleza supraestatal. Luego de la reforma de 1994, la jurisdicción constitucional en materia de protección de los derechos fundamentales ha dejado de pertenecer exclusivamente al Estado argentino, en razón que puede acudirse a la jurisdicción supraestatal para perseguir la restauración de una regla jurídica tutelada por la CADH. Tal hipótesis no es ni habitual ni ordinaria y sólo procede, además, una vez que se encuentran reunidos una serie de rigurosos recaudos, entre los que ocupa el primer rango el de la interposición y agotamiento de los recursos previstos al respecto por la esfera jurisdiccional estatal, conforme a los principios del derecho internacional generalmente reconocidos.

Por otro lado, en el artículo 64 de la CADH se contempla la posibilidad de que un Estado miembro consulte a la Corte Interamericana acerca de la interpretación de la Convención o de otros tratados concernientes a la protección de los derechos humanos en los Estados Americanos, o acerca de la compatibilidad entre cualquiera de las leyes internas del Estado y los mencionados instrumentos internacionales. Las respuestas a dichas consultas son las «opiniones consultivas». Entiendo, por lo tanto, que cuando un Estado Parte de la Convención formula el pedido para que la Corte Interamericana emita una opinión consultiva está garantizando o intentando garantizar la coherencia de su sistema jurídico con el sistema regional protectorio de los derechos humanos. Podría entenderse que estas respuestas del tribunal tendrían aptitud para operar como una suerte de garantía de la constitución de fuente estatal, conforme son éstos descriptos ut supra (punto V.2.A).

\section{CLAUSURA}

Uno. En las líneas anteriores se cumple el firme propósito: la comprensión fáctica y la comprensión normativa de la constitución. Giran sobre nosotros las alternativas, porque ninguna cosa o estado de cosas en el mundo puede ser una norma y no ser al mismo tiempo una norma para pasar a ser, o convertirse en, un hecho, o viceversa. Las constituciones nacen y se desarrollan como fácticas o

que será definitivo e inapelable, el tribunal se encuentra autorizado para decidir si, en el caso que le sea sometido, hubo o no violación de un derecho o libertad protegido por la Convención. Si lo hubo, la Corte dispondrá que se garantice al lesionado en el goce de su derecho o libertad conculcados, disponiendo asimismo si fuere procedente que se reparen las consecuencias de la medida o situación que ha configurado la vulneración de esos derechos y el pago de una justa indemnización a la parte lesionada. El art. 68 dispone que los Estados Parte se comprometen a cumplir con la decisión de la Corte en todo caso en que sean partes. 
normativas. No creo que exista debate de carácter abstracto que supere el marco de referencia. Con alivio se puede afirmar que no hay existentes mundanos, cuya entidad fuese hecho y norma o viceversa, en el mismo tiempo y espacio.

Mis notas registran los dos enfoques. La finalidad de los pensamientos presentados, especialmente en la sección II — como se dijo mucho antes de ahoraes única: servir para pensar. Retratar, pues, con la mayor fidelidad la distinción entre hecho y norma en las diferentes concepciones.

Dos. La constitución nace, en general, dando forma a una realidad política y económica que la precede. Organiza fundamentalmente al Estado, nutre su dirección política y decide la unidad jurídica. Que casi todos los estados tengan una constitución escrita permite trazar semejanzas y hasta identidades normativas. Sin embargo, la peculiar forma de ordenar de cada norma es invariable y solamente realizable en un determinado contexto espacial y temporal: esa cosa llamada Estado!

Tres. La constitución como norma se encuentra inserta, siempre, en un «contexto de cultura» ${ }^{76}$. Cultura significa lo creado por el hombre, en diferenciación a la naturaleza. Ciertamente, contexto es un concepto puente porque tiene relevancia para concretar la significación de norma, desde el mismo momento que obliga a incluir, en el propio significado, todo lo que la rodea, es decir: el entorno del sistema.

Cuatro. La constitución no es una creación divina del mundo. Se trata de una modesta y limitada invención humana. Probablemente, la mejor que se conoce, hasta ahora, para robustecer la ciudadanía y organizar el poder comunitario. Hecha por hombres y para hombres que, con sus ilusiones exageradas y detallistas, muchas veces, intentan vanamente por medio de fórmulas normativas encerrar todo el porvenir, o peor todavía: deducirlo.

Cinco. El mundo constitucional es un cosmos jurídico que fundamenta la organización estatal. El ciudadano es el sujeto central, porque precisamente él es la medida de las $\operatorname{cosas}^{77}$. La asociación de ciudadanos, la elevación a la enésima potencia del poder individual, sigue consistiendo en la concurrencia a un contrato. Constitución o contrato son palabras equivalentes, porque son la

76 V. Häberle, Peter: «La constitución en el contexto», Anuario Iberoamericano de Justicia constitucional, $\mathrm{n}^{\circ}$ 7, Madrid, 2003, pp. 223-245.

77 En sentido semejante al atribuido a Protágoras: el hombre es la medida de todas las cosas, de las que son en cuanto que son y de las que no son en cuanto que no son, entendiendo por «medida» la norma y por «cosas» lo real; de forma que él podría decir que el hombre es la norma de todo lo real, de lo que es en cuanto que es y de lo que no es en cuanto que no es. V. Protágoras y Gorgias: Fragmentos y testimonios, Hyspámerica, Buenos Aires, 1980, p. 51. 
forma de la organización pactada por intermedio de la libertad de cada uno de los ciudadanos, que no todos disponen y que no todos pueden ejercer por igual.

Seis. Puesta la constitución, su significado se desenvuelve entre la lealtad a la redacción originaria, la actualización de su campo semántico y la estipulación de la necesidad de su cambio.

Siete. El Derecho constitucional es el derecho constituyente, fundamento del todo el Derecho estatal. La edificación activa, eficiente y fundamental del Derecho constitucional la concreta la CFA.

Ocho. La CFA crea los fundamentos indispensables para la convivencia comunitaria. La CFA, al conferir reconocimiento a los derechos y organizar el poder y su control, norma el perímetro básico de su propia permanencia en el tiempo; es decir: da fundamento a la coexistencia actual de los ciudadanos y se proyecta al futuro con la pretensión de desarrollarla en armonía y paz.

Noveno. Distinguir el universo de la CFA, señalar sus partes, permite elaborar la correcta identificación y ulterior sistematización de sus componentes. Además, el funcionamiento cabal del sistema se comprende con la presentación y descripción de las garantías.

Diez. Este relato es reducible, quizá, a una fórmula: la constitución y su contemplación como norma, en la peculiar comprensión de las partes y mecanismos de la CFA, que hacen a su forma de obligar a los ciudadanos y al poder estatal.

Title:

ON THE CONSTITUTION. CONCEPT, STRUCTURE, AND DEVICES

\section{Summary:}

I. Introduction: facts and ideas. II. What is a constitution? Inventory. II.1. Preliminary considerations. II.2. Meanings II.3. Quick look at the historical path of «constitution». II.3.A. Normative strength of facts. II.3.B. Normative paradigms. II.3.B bis. Interlude: Thomas Paine's Utopian ideals. II.3.C. The sheet of paper. II.3.D. Contesting Carl Schmitt. II.3.E. Pure theory of Law. II.4. Interlude: Germán J. Bidart Campos's trialism. III. Meaning of constitution. (i) Supremacy. (ii) Hierarchy. (iii) Elasticity. (iv) Openness. (v) Unity. (vi) Consistency. (vii) Sovereignty. (viii) Organisation. (ix) Identity. (x) Enforcement. IV. Parties. IV.1. Basic introduc- 
tion. IV.2. Strict structure. IV.3. Mere declarations. IV.3.A. The preamble of a constitution. IV.3.B. Temporary provisions. IV.4. Basic rights and duties. IV.4.A. Basic rights. IV.4.B. Duties or obligations. IV.5. Power and its control. IV.6. Reform. V. Guarantee devices. V.1. Design. V.2.A. Constitution guarantees. V.2.A bis. Interval. Interpretation and judicial review. V.2.B. Guarantees of basic rights. V.2.C. The organic guarantee for the defence of basic rights. V.2.D. Supranational guarantee for the defence of basic rights established by the law of a constitution. VI. Closing.

\title{
Resumen:
}

Se evalúan diferentes comprensiones de «constitución» ensayadas en la historia de las ideas. Se opta por la concepción normativa: la constitución es un producto cultural, fundamento de todo el sistema jurídico. La comprensión elegida, se aplica, inmediatamente, al lenguaje prescriptivo que emana de Constitución Argentina y se destacan sus partes y su mecanismo fundamental: las garantías. Concluyentemente, la constitución sigue siendo un contrato, político y acordado por cada uno de lo ciudadanos que integran las generaciones, ya sea para facilitar y desarrollar la convivencia (expectable), ya sea para obstaculizar la coexistencia (no expectable); al fin y al cabo: es un instrumento humano, perfectible, como toda su obra.

\begin{abstract}
:
The different meanings of «constitution» postulated throughout the history of ideas are analysed. The normative concept is chosen: the constitution is a cultural product, a base of the entire legal system. The meaning chosen is immediately applied to the prescriptive language that stems from the Argentine Constitution, and its parts and its main device are highlighted: guarantees. In conclusion, the constitution still is a political contract agreed upon by each of the citizens of different generations, to enable and enhance coexistence (expected), or to hinder coexistence (not expected). At the end of the day, it is a human instrument and, as any human creation, it is perfectible.
\end{abstract}

Palabras clave:

Constitución. Cultura. Garantías. Contrato. Ciudadanos. Instrumento. Convivencia.

Keywords:

Constitution. Culture. Guarantees. Contract. Citizens. Instrument. Coexistence. 